Corrected: Author correction

ARTICLE

DOI: $10.1038 / s 41467-018-05110-x$

\title{
Single-pot glycoprotein biosynthesis using a cell- free transcription-translation system enriched with glycosylation machinery
}

\author{
Thapakorn Jaroentomeechai ${ }^{1}$, Jessica C. Stark ${ }^{2,3,4}$, Aravind Natarajan (10 ${ }^{5}$, Cameron J. Glasscock (iD ${ }^{1}$, \\ Laura E. Yates ${ }^{1}$, Karen J. Hsu ${ }^{6}$, Milan Mrksich ${ }^{4,7,8,9}$, Michael C. Jewett (iD ${ }^{2,3,4}$ \& Matthew P. DeLisa (1) ${ }^{1,5}$
}

The emerging discipline of bacterial glycoengineering has made it possible to produce designer glycans and glycoconjugates for use as vaccines and therapeutics. Unfortunately, cell-based production of homogeneous glycoproteins remains a significant challenge due to cell viability constraints and the inability to control glycosylation components at precise ratios in vivo. To address these challenges, we describe a novel cell-free glycoprotein synthesis (CFGpS) technology that seamlessly integrates protein biosynthesis with asparagine-linked protein glycosylation. This technology leverages a glyco-optimized Escherichia coli strain to source cell extracts that are selectively enriched with glycosylation components, including oligosaccharyltransferases (OSTs) and lipid-linked oligosaccharides (LLOs). The resulting extracts enable a one-pot reaction scheme for efficient and site-specific glycosylation of target proteins. The CFGpS platform is highly modular, allowing the use of multiple distinct OSTs and structurally diverse LLOs. As such, we anticipate CFGpS will facilitate fundamental understanding in glycoscience and make possible applications in on demand biomanufacturing of glycoproteins.

\footnotetext{
${ }^{1}$ Robert Frederick Smith School of Chemical and Biomolecular Engineering, Cornell University, Ithaca, NY 14853, USA. ${ }^{2}$ Department of Chemical and Biological Engineering, Northwestern University, Evanston, IL 60208, USA. ${ }^{3}$ Chemistry of Life Processes Institute, 2170 Campus Drive, Evanston, IL 602083120, USA. ${ }^{4}$ Center for Synthetic Biology, Northwestern University, 2145 Sheridan Road, Evanston, IL 60208-3120, USA. ${ }^{5}$ Department of Microbiology, Cornell University, Ithaca, NY 14853, USA. ${ }^{6}$ Department of Mechanical Engineering, Northwestern University, 2145 Sheridan Rd Technological Institute B224, Evanston, IL 60208-3120, USA. ${ }^{7}$ Department of Chemistry, Northwestern University, Evanston, IL 60208, USA. ${ }^{8}$ Department of Cell and Molecular Biology, Northwestern University, Chicago, IL 60611, USA. ${ }^{9}$ Department of Biomedical Engineering, Northwestern University, Evanston, IL 60208, USA. These authors contributed equally: Thapakorn Jaroentomeechai, Jessica C. Stark. Correspondence and requests for materials should be addressed to M.C.J. (email: m-jewett@northwestern.edu) or to M.P.D. (email: md255@cornell.edu)
} 
A sparagine-linked ( $N$-linked) protein glycosylation is one of the most common post-translational modifications in eukaryotes, and profoundly affects protein properties such as folding, stability, immunogenicity, and pharmacokinetics ${ }^{1-3}$. The attached $\mathrm{N}$-glycans can participate in a wide spectrum of biological processes such as immune recognition/response ${ }^{4,5}$ and stem cell fate ${ }^{6}$. Moreover, the intentional engineering of proteinassociated glycans can be used to manipulate protein therapeutic properties such as enhancing in vivo activity and half-life ${ }^{7}$.

At present, however, the inherent structural complexity of glycans and the corresponding difficulties producing homogeneously glycosylated proteins have slowed advances in our understanding of glycoprotein functions and limited opportunities for biotechnological applications. Moreover, because glycan biosynthesis is neither template-driven nor genetically encoded, glycans cannot be produced from recombinant DNA technology. Instead, $\mathrm{N}$-glycans are naturally made by coordinated expression of multiple glycosyltransferases (GTs) across several subcellular compartments. This mode of biosynthesis combined with the lack of a strict proofreading system results in inherent glycan heterogeneity and accounts for the large diversity of structures in the expressed glycan repertoire of a cell or organism ${ }^{8,9}$. Further complicating matters is the paucity of structure-function relationships for GTs, which hinders a priori prediction of glycan structure. Altogether, these factors have frustrated production of homogeneous glycans and glycoconjugates in biological systems and restricted our capacity to elucidate the biochemical and biophysical effects of glycans on the proteins to which they are attached. Thus, there is an unmet need for a technology capable of rapidly producing useful quantities of proteins featuring user-specified glycosylation for biochemical and structural biology studies.

Recent pioneering efforts in glycoengineering of cellular systems including mammalian ${ }^{10}$, yeast ${ }^{11}$, and bacterial cells ${ }^{12}$ have expanded our ability to reliably synthesize chemically defined glycans and glycoproteins. Despite the promise of these systems, protein expression yields often remain low and design-build-test (DBT) cycles-iterations of re-engineering organisms to test new sets of enzymes-can be slow. One promising alternative to cellbased systems is cell-free protein synthesis (CFPS) in which protein synthesis occurs in vitro without using intact, living cells. Recently, a technical renaissance has revitalized CFPS systems to help meet increasing demands for simple and efficient protein synthesis, with Escherichia coli-based CFPS systems now exceeding grams of protein per liter reaction volume ${ }^{13}$, with the ability to support co- or post-translational modifications ${ }^{14-18}$. As a complement to in vivo expression systems, cell-free systems offer several potential advantages. First, the open nature of the reaction allows the user to directly influence biochemical systems of interest. As a result, new components can be added or synthesized, and maintained at precise concentrations ${ }^{19,20}$. Second, cell-free systems bypass viability constraints making possible the production of proteins at titers that would otherwise be toxic in living cells ${ }^{21}$. Third, processes that take days or weeks to design, prepare, and execute in vivo can be done more rapidly in a cellfree system ${ }^{22,23}$, leading to high-throughput production campaigns on a whole-proteome scale ${ }^{24}$ with the ability to automate ${ }^{25}$.

Unfortunately, CFPS systems have been limited by their inability to co-activate efficient protein synthesis and glycosylation. The best characterized and most widely adopted CFPS systems use E. coli lysates to activate in vitro protein synthesis, but these systems are incapable of making glycoproteins because E. coli lacks endogenous glycosylation machinery. Glycosylation is possible in some eukaryotic CFPS systems, including those prepared from insect cells ${ }^{26}$, trypanosomes ${ }^{27}$, hybridomas ${ }^{28}$, or mammalian cells ${ }^{29-31}$. However, these platforms are limited to endogenous machinery for performing glycosylation, meaning that (i) the possible glycan structures are restricted to those naturally synthesized by the host cells and (ii) the glycosylation process is carried out in a black box and thus difficult to engineer or control. Additionally, eukaryotic CFPS systems are technically difficult to prepare, often requiring supplementation with microsomes ${ }^{31-33}$, and suffer from inefficient protein synthesis and glycosylation yields due to inefficient trafficking of nascent polypeptide chains to microsomes ${ }^{27,33}$.

Despite progress in eukaryotic cell-free systems, cell-free extracts from bacteria like $E$. coli offer a blank canvas for studying glycosylation pathways, provided they can be activated in vitro. A recent work from our group highlights the ability of CFPS to enable glycoprotein synthesis in bacterial cell-free systems by augmenting commercial $E$. coli-based cell-free translation systems with purified components from a bacterial $N$-linked glycosylation pathway ${ }^{34}$. While these results established the possibility of $E$. coli lysate-based glycoprotein production, there are several drawbacks of using purified glycosylation components that limit system utility. First, preparation of the glycosylation components required time-consuming and cost-prohibitive steps, namely purification of a multipass transmembrane oligosaccharyltransferase (OST) enzyme and organic solvent-based extraction of lipid-linked oligosaccharide (LLO) donors from bacterial membranes. These steps significantly lengthen the process development timeline, requiring 3-5 days each for preparation of the LLO and OST components, necessitate skilled operators and specialized equipment, and result in products that must be refrigerated and are stable for only a few months to a year. Second, glycoproteins were produced using a sequential translation/glycosylation strategy, which required $20 \mathrm{~h}$ for cellfree synthesis of the glycoprotein target and an additional $12 \mathrm{~h}$ for post-translational protein glycosylation.

Here, we addressed these drawbacks by developing an integrated cell-free glycoprotein synthesis (CFGpS) technology that bypasses the need for purification of OSTs and organic solventbased extraction of LLOs. The creation of this streamlined CFGpS system was made possible by two important discoveries: (i) crude extract prepared from the glyco-optimized E. coli strain, CLM24, is able to support cell-free protein expression and $\mathrm{N}$-linked glycosylation; and (ii) OST- and LLO-enriched extracts derived from CLM24 are able to reproducibly co-activate protein synthesis and $\mathrm{N}$-glycosylation in a reaction mixture that minimally requires priming with DNA encoding the target glycoprotein of interest. Importantly, the CFGpS system decouples production of glycoprotein synthesis components (i.e., OSTs, LLOs, translation machinery) and the glycoprotein target of interest, providing significantly reduced cell viability constraints compared to in vivo systems. The net result is a one-pot bacterial glycoprotein biosynthesis platform whereby different acceptor proteins, OSTs, and/or oligosaccharide structures can be functionally interchanged and prototyped for customizable glycosylation.

\section{Results}

Efficient CFGpS using extracts from glyco-optimized chassis strain. To develop a one-pot glycoprotein synthesis system, the bacterial protein glycosylation locus $(p g l)$ present in the genome of the Gram-negative bacterium Campylobacter jejuni was chosen as a model glycosylation system (Fig. 1). This gene cluster encodes an asparagine-linked ( $N$-linked) glycosylation pathway that is functionally similar to that of eukaryotes and archaea ${ }^{35}$, involving a single-subunit OST, PglB, that catalyzes the en bloc transfer of a preassembled $1.4 \mathrm{kDa}$ GlcGalNAc ${ }_{5}$ Bac heptasaccharide (where Bac is bacillosamine) from the lipid carrier undecaprenyl pyrophosphate (Und-PP) onto asparagine residues in a conserved motif 


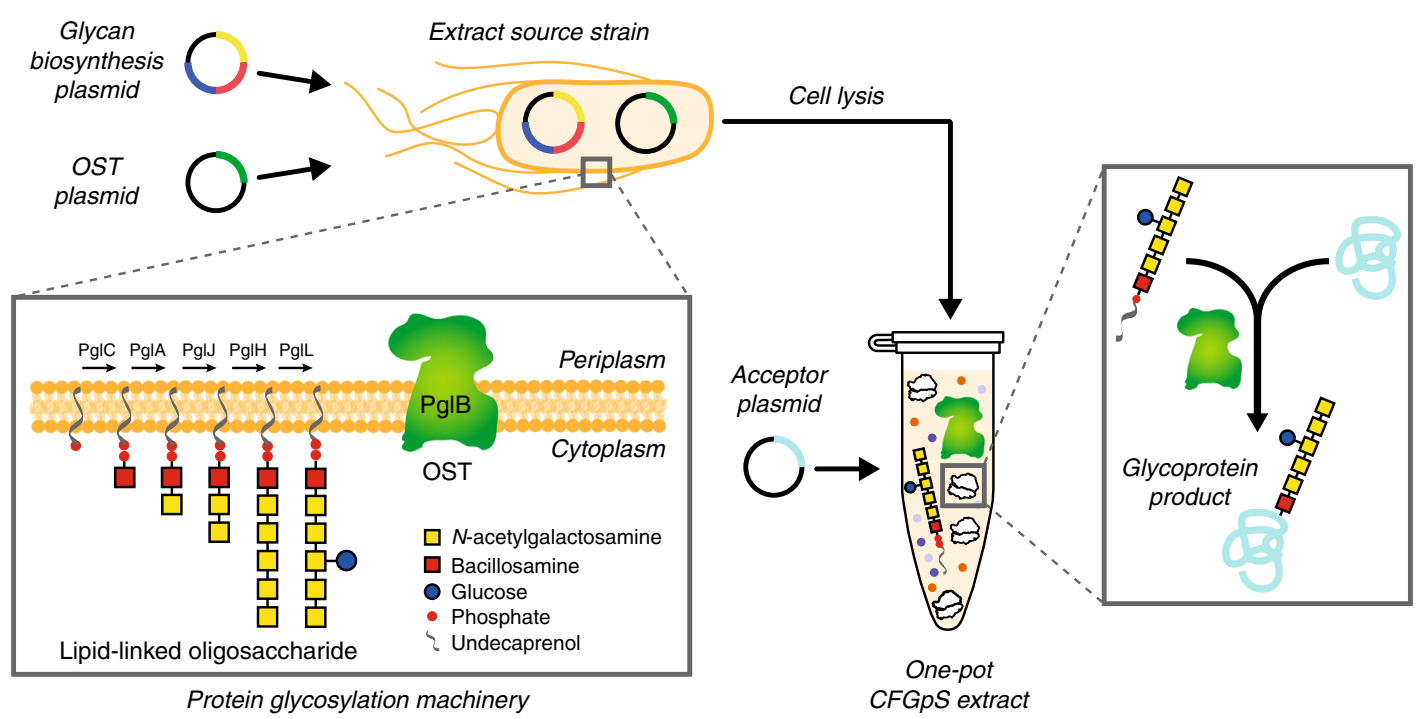

Fig. 1 Schematic of single-pot CFGpS technology. Glycoengineered E. coli that are modified with (i) genomic mutations that benefit glycosylation reactions and (ii) plasmid DNA for producing essential glycosylation components (i.e., OSTs, LLOs) serve as the source strain for producing crude S30 extracts. Candidate glycosylation components can be derived from all kingdoms of life and include single-subunit OSTs like C. jejuni PgIB and LLOs bearing N-glycans from C. jejuni that are assembled on Und-PP by the Pgl pathway enzymes. Following extract preparation by lysis of the source strain, one-pot biosynthesis of $\mathrm{N}$-glycoproteins is initiated by priming the extract with DNA encoding the acceptor protein of interest

$\left(\mathrm{D} / \mathrm{E}-\mathrm{X}_{-1}-\mathrm{N}-\mathrm{X}_{+1}-\mathrm{S} / \mathrm{T}\right.$, where $\mathrm{X}_{-1}$ and $\mathrm{X}_{+1}$ are any residues except proline) within acceptor proteins. PglB was selected because we previously showed that $\mathrm{N}$-glycosylated acceptor proteins were reliably produced when cell-free translation kits were supplemented with (i) C. jejuni PglB (CjPglB) purified from E. coli cells and (ii) LLOs extracted from glycoengineered $E$. coli cells expressing the enzymes for producing the $C$. jejuni $N$-glycan on Und-PP $(C j L L O s)^{34}$. Additionally, PglB has been used in engineered $E$. coli for transferring eukaryotic trimannosyl chitobiose glycans (mannose $_{3}-\mathrm{N}$-acetylglucosamine $2, \mathrm{Man}_{3} \mathrm{GlcNAc}_{2}$ ) to specific asparagine residues in target proteins ${ }^{12}$.

Establishing a CFGpS system first required crude cell extracts suitable for glycoprotein synthesis; hence, we selected E. coli strain CLM24 that was previously optimized for in vivo protein glycosylation ${ }^{36}$. CLM24 has two attributes that we hypothesized would positively affect cell-free protein glycosylation. First, CLM24 does not synthesize $O$-polysaccharide antigen due to an inactivating insertion in w $b b L$, which encodes a rhamnosyl transferase that transfers the second sugar of the O16 subunit to Und-PP ${ }^{37}$. Thus, absence of WbbL should allow uninterrupted assembly of engineered glycans, such as the C. jejuni heptasaccharide, on Und-PP. Second, CLM24 cells lack the waaL gene, which encodes the ligase that transfers $O$-polysaccharide antigens from Und-PP to lipid A-core. Because WaaL can also promiscuously transfer engineered glycans that are assembled on Und-PP ${ }^{12,38}$, the absence of this enzyme should favor accumulation of target glycans on Und-PP.

To determine whether CLM24 could be used as a chassis strain to support integrated cell-free transcription, translation, and glycosylation, we first prepared crude S30 extract from these cells using a rapid and robust procedure for extract preparation based on sonication $^{39}$. Then, $15-\mu \mathrm{L}$ batch-mode, sequential CFGpS reactions were performed using CLM24 crude extract that was supplemented with the following: (i) an OST catalyst in the form of purified $\mathrm{CjPglB}^{34}$; (ii) oligosaccharide donor in the form of CjLLOs that were isolated by organic solvent extraction from the membrane fraction of glycoengineered E. coli cells ${ }^{34}$; and (iii) plasmid DNA encoding the model acceptor protein scFv13-R4 ${ }^{\mathrm{DQNAT}}$, an anti- $\beta$ galactosidase $(\beta$-gal) single-chain variable fragment $(\mathrm{scFv})$ antibody modified C-terminally with a single DQNAT motif ${ }^{12}$. The glycosylation status of scFv13-R4 ${ }^{\text {DQNAT }}$ was analyzed by SDSPAGE and immunoblotting with an anti-polyhistidine (anti-His) antibody or hR6 serum that is specific for the $C$. jejuni heptasaccharide glycan ${ }^{40}$. Following an overnight reaction at $30^{\circ}$ $\mathrm{C}$, highly efficient glycosylation was achieved as evidenced by the mobility shift of scFv13-R4 ${ }^{\mathrm{DQNAT}}$ entirely to the monoglycosylated (g1) form in anti-His immunoblots and the detection of the C. jejuni glycan attached to scFv13-R4 ${ }^{\mathrm{DQNAT}}$ by hR6 serum (Fig. 2a). For synthesis of scFv13-R4 DQNAT, the reaction mixture was modified to be oxidizing, through the addition of iodoacetamide and a 3:1 ratio of oxidized and reduced glutathione, demonstrating the flexibility of CFGpS reaction conditions for producing eukaryotic glycoprotein targets. The efficiency achieved in this CFGpS system rivaled that of an in vitro glycosylation reaction in which the scFv13-R4 ${ }^{\mathrm{DQNAT}}$ acceptor protein was expressed and purified from E. coli, and then incubated overnight with purified CjPglB and extracted CjLLOs (Fig. 2a). As expected, when CjPglB was omitted from the reaction, the scFv13-R4 DQNAT acceptor protein was produced only in the aglycosylated $(\mathrm{g} 0)$ form. The results generated here with CLM24 extract are consistent with our earlier studies using an E. coli S30 extract-based CFPS system or purified translation machinery ${ }^{34}$, and establish that the C. jejuni $N$ linked protein glycosylation mechanism can be functionally reconstituted outside the cell.

Expanding the glycan repertoire of cell-free glycosylation. To date, only the $C$. jejuni glycosylation pathway has been reconstituted in vitro ${ }^{34}$, and it remains an open question whether our system can be reconfigured with different LLOs and OSTs. Therefore, to extend the range of glycan structures beyond the $C$. jejuni heptasaccharide, we performed glycosylation reactions in which the solvent-extracted CjLLOs used above were replaced with oligosaccharide donors extracted from E. coli cells carrying alternative glycan biosynthesis pathways. These included LLOs bearing the following glycan structures: (i) native C. lari hexasaccharide $N$-glycan ${ }^{40}$; (ii) engineered GalNAc ${ }_{5}$ GlcNAc based on the Campylobacter lari hexasaccharide $\mathrm{N}$-glycan ${ }^{41}$; (iii) native Wolinella succinogenes hexasaccharide $N$-glycan containing three $216-\mathrm{Da}$ monosaccharides and an unusual 232-Da 
a

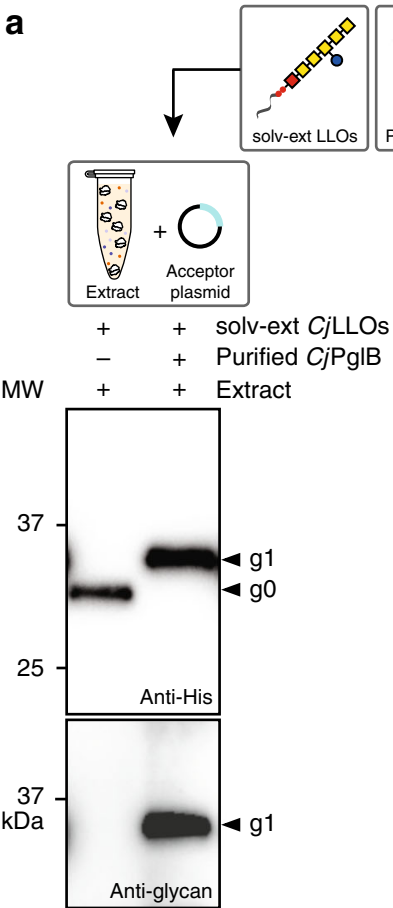

b

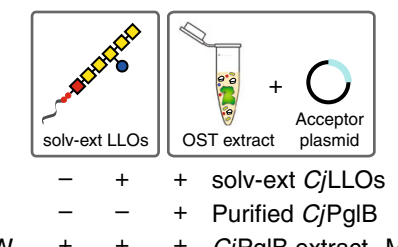

$\mathrm{MW}+++$ CjPglB extract MW

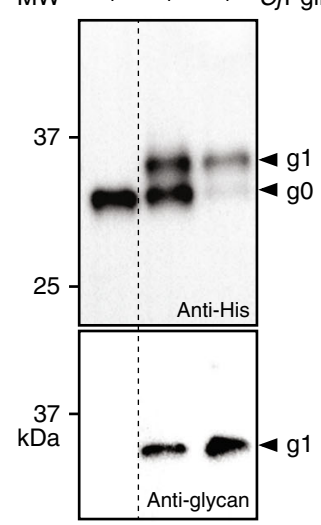

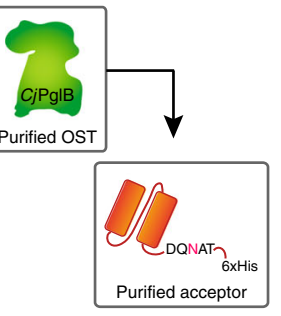
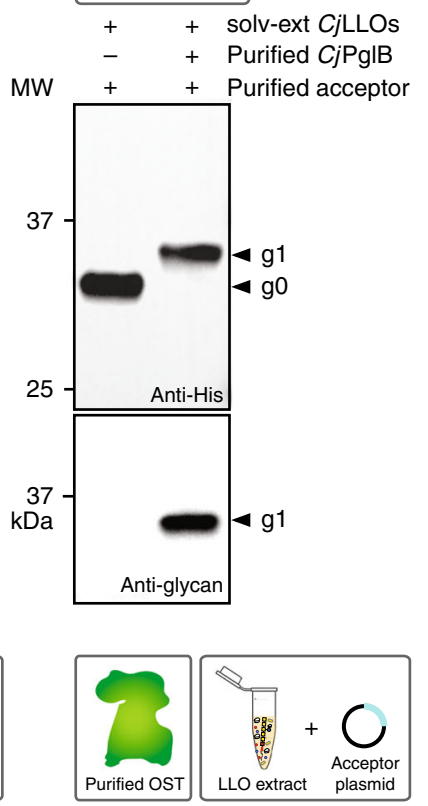

+ solv-ext CjLLOs -++ Purified CjPglB $+\quad+$ CjLLOs extract

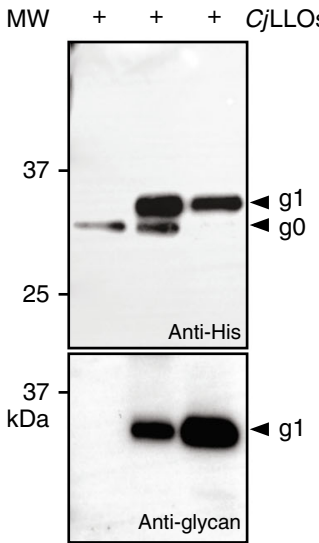

residue at the non-reducing end ${ }^{42}$; (iv) engineered E. coli O9 primer-adaptor glycan, $\mathrm{Man}_{3} \mathrm{GlcNAc}$, that links the O-chain and core oligosaccharide in the lipopolysaccharide of several E. coli and Klebsiella pneumoniae serotypes ${ }^{43}$; and (v) eukaryotic trimannosyl core $N$-glycan, $\mathrm{Man}_{3} \mathrm{GlcNAc}_{2}{ }^{12}$. Glycosylation of scFv13-R4 ${ }^{\text {DQNAT }}$ with each of these different glycans was observed to occur only in the presence of CjPglB (Fig. 3). It should be noted that $100 \%$ glycosylation conversion was observed for each of these glycans except for the $\mathrm{Man}_{3} \mathrm{GlcNAc}_{2} \mathrm{~N}$-glycan, which had a conversion of $\sim 40 \%$ as determined by densitometry analysis. While the reasons for this lower efficiency remain unclear, conjugation efficiency of the same $\mathrm{Man}_{3} \mathrm{GlcNAc}_{2}$ glycan to acceptor proteins in vivo was reported to be even lower $(<5 \%)^{12,44}$. Hence, transfer of $\mathrm{Man}_{3} \mathrm{GlcNAc}_{2}$ to acceptor proteins in vitro appears to overcome some of the yet-to-be-identified bottlenecks of in vivo glycosylation. This result is likely due to the

Fig. 2 Extract from glyco-optimized chassis strain supports CFGpS. a (left) Western blot analysis of scFv13-R4 ${ }^{\text {DQNAT }}$ produced by crude CLM24 extract supplemented with purified CjPgIB and organic solvent-extracted (solv-ext) CjLLOs, and primed with plasmid pJL1-scFv13-R4 DQNAT. (right) Western blot analysis of in vitro glycosylation reaction using purified scFv13-R4 DQNAT acceptor protein that was incubated with purified CjPgIB and organic solvent-extracted (solv-ext) CjLLOs. Control reactions (lane 1 in each panel) were performed by omitting purified CjPgIB. b (left) Western blot analysis of scFv13-R4 ${ }^{\text {DQNAT }}$ produced by crude CLM24 extract selectively enriched with $\mathrm{CjPgIB}$ from heterologous overexpression from pSF-CjPgIB. (right) Western blot analysis of scFv13-R4 ${ }^{\text {DQNAT }}$ produced by crude CLM24 extract selectively enriched with CjLLOs from heterologous overexpression from pMW07-pgl $\Delta \mathrm{B}$. Reactions were primed with plasmid pJL1-scFv13-R4 $4^{\text {DQNAT }}$ and supplemented with purified CjPgIB and organic solvent-extracted (solv-ext) CjLLOs as indicated. Control reactions (lane 1 in each panel) were performed by omitting solv-ext CjLLOs in (left) or purified CjPgIB (right) in (b). Blots were probed with anti-hexa-histidine antibody (anti-His) to detect the acceptor protein or hR6 serum (antiglycan) to detect the $\mathrm{N}$-glycan. Arrows denote aglycosylated ( $\mathrm{g} 0$ ) and singly glycosylated (g1) forms of scFv13-R4 DQNAT. Molecular weight (MW) markers are indicated at left. Results are representative of at least three biological replicates

opportunity with CFGpS to control the concentration of reaction components, for example, providing a higher local concentration of LLO donors. Importantly, scFv13-R4 DQNAT was uniformly decorated with a $\mathrm{Man}_{3} \mathrm{GlcNAc}_{2}$ glycan as evidenced by liquid chromatography-mass spectrometry (LC-MS). Specifically, the only major glycopeptide product to be detected was a triplycharged ion containing an $N$-linked pentasaccharide with $\mathrm{m} / z=$ 1032.4583, consistent with the $\mathrm{Man}_{3} \mathrm{GlCNAc}_{2}$ glycoform (Supplementary Fig. 1). The tandem MS spectra for this triply-charged glycopeptide yielded an excellent $y$-ion series and a good b-ion series enabling conclusive determination of the tryptic glycopeptide sequence and attachment of the $\mathrm{Man}_{3} \mathrm{GlcNAc}_{2}$ glycoform at residue N273 of the scFv13-R4 ${ }^{\text {DQNAT }}$ protein (Supplementary Fig. 2). Taken together, these results demonstrate that structurally diverse glycans, including those that resemble eukaryotic structures, can be modularly interchanged in cell-free glycosylation reactions.

Extracts enriched with OSTs or LLOs co-activate glycosylation. To circumvent the need for exogenous addition of purified glycosylation components, we hypothesized that heterologous overexpression of OST or GT enzymes directly in the chassis strain would yield extracts that are selectively enriched with the requisite glycosylation components. This strategy was motivated by a recent metabolic engineering approach whereby multiple cell-free lysates were each selectively enriched with an overexpressed metabolic enzyme and then combinatorially mixed to construct an intact pathway ${ }^{20,22}$. However, a fundamental difference in our system is the fact that the OST and LLOs are not soluble components but instead reside natively in the inner cytoplasmic membrane. This is potentially problematic because of the significant breakup of the cell membrane during S30 extract preparation. However, it has been established that fragments of the E. coli inner membrane reform into membrane vesicles, some of which are inverted but others that are orientated properly ${ }^{45}$, and thus could supply the OST and LLOs in a functionally accessible conformation within the extract.

To test this hypothesis, we used a high-pressure homogenization method to prepare crude S30 extract from CLM24 cells carrying a plasmid-encoded copy of $C j P g l B$ such that the resulting cell-free lysates were selectively enriched with detectable quantities of full-length OST enzyme as confirmed by Western 

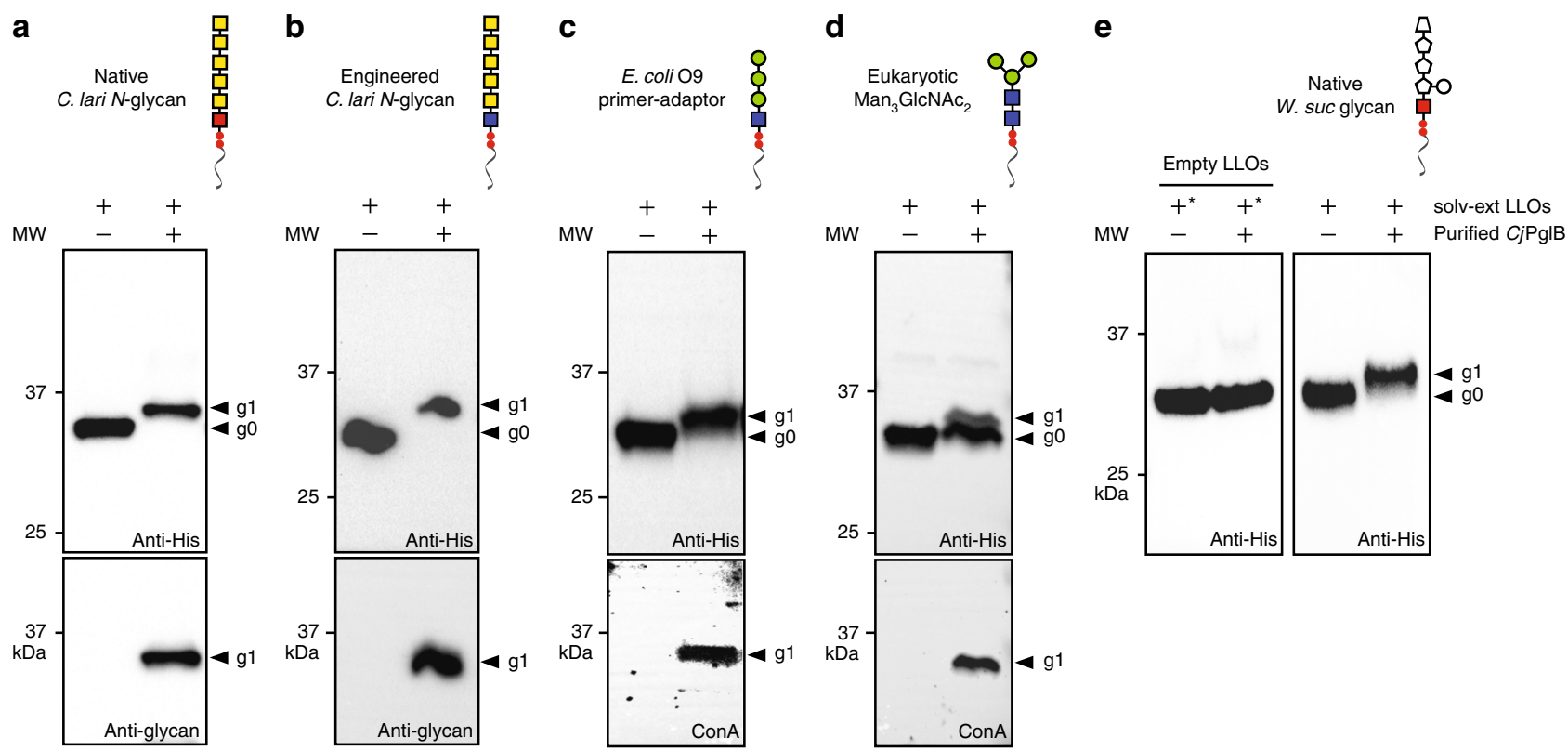

Fig. 3 Expanding cell-free glycosylation with different oligosaccharide structures. Western blot analysis of in vitro glycosylation reaction products generated with purified scFv13-R4 ${ }^{\text {DQNAT }}$ acceptor protein, purified CjPgIB, and organic solvent-extracted (solv-ext) LLOs from cells carrying: a plasmid pACYCpg/4 for making the native $\mathrm{C}$. lari hexasaccharide $\mathrm{N}$-glycan; b plasmid pACYCpgl2 for making the engineered $\mathrm{C}$. lari hexasaccharide $\mathrm{N}$-glycan; c plasmid pO9-PA for making the E. coli O9 'primer-adaptor' Man ${ }_{3}$ GlcNAc structure; d plasmid pConYCGmCB for making the eukaryotic Man $\mathrm{GlcNAc}_{2} \mathrm{~N}$-glycan structure; and e fosmid pEpiFOS-5pgl5 for making the native $\mathrm{W}$. succinogenes hexasaccharide $\mathrm{N}$-glycan. Reactions were run at $30^{\circ} \mathrm{C}$ for $16 \mathrm{~h}$. Blots were probed with antiHis antibody to detect the acceptor protein and one of the following: hR6 serum that cross-reacts with the native and engineered C. lari glycans or ConA lectin that binds internal and non-reducing terminal $\alpha$-mannosyl groups in the Man ${ }_{3} \mathrm{GlcNAc}$ and $\mathrm{Man}_{3} \mathrm{GlcNAc}_{2}$ glycans. Because structural determination of the $\mathrm{W}$. succinogenes $\mathrm{N}$-glycan is currently incomplete, and because there are no available antibodies, the protein product bearing this $\mathrm{N}$-glycan was only probed with the anti-His antibody. As an additional control for this glycan, we included empty LLOs prepared from the same host strain but lacking the pEpiFOS-5pgl5 fosmid (left hand panel, "+" signs marked with an asterisk). Arrows denote aglycosylated ( $\mathrm{g} 0$ ) and singly glycosylated ( $\mathrm{g} 1)$ forms of the scFv13-R4 ${ }^{\text {DQNAT }}$ protein. Molecular weight (MW) markers are indicated at left. Results are representative of at least three biological replicates

blot analysis (Supplementary Fig. 3a). Similarly, crude S30 extract from CLM24 cells overexpressing the C. jejuni glycan biosynthesis enzymes produced lysate that was selectively enriched with CjLLOs as confirmed by dot blot analysis with hR6 serum (Supplementary Fig. 3b). It should be noted that the amount of $C j L L O s$ enriched in the crude extract rivaled that produced by the significantly more tedious organic solvent extraction method. Importantly, when $15-\mu \mathrm{L}$ batch-mode sequential CFGpS reactions were performed using the OST-enriched crude extract that was supplemented with solvent-extracted CjLLOs and plasmid DNA encoding scFv13-R4 ${ }^{\mathrm{DQNAT}}$, clearly detectable glycosylation of the acceptor protein was observed (Fig. 2b). The conversion of acceptor protein to glycosylated product was $\sim 50 \%$; however, further supplementation with purified $C j P g l B$ increased the conversion to nearly $100 \%$, indicating that the amount of OST in the crude extract might have been limiting under the conditions tested. When similar CFGpS reactions were performed using the CjLLO-enriched crude extract supplemented with purified CjPglB and plasmid DNA encoding scFv13-R4 DQNAT, $>80 \%$ glycosylation of the acceptor protein was observed, which reached $100 \%$ when additional donor glycans were supplemented (Fig. 2b).

Modularity enables glycosylation components to be interchanged. Given the open nature of cell-free biosynthesis, we postulated that it should be possible to functionally interchange and prototype alternative biochemical reaction components. One straightforward way that this can be accomplished is by combining separately prepared extracts, each of which is selectively enriched with a given enzyme, such that the resulting reaction mixture comprises a functional biological pathway ${ }^{20,22}$. As proof of this concept, separately prepared CjLLO and CjPglB extracts were mixed and subsequently primed with DNA encoding the scFv13-R4 DQNAT acceptor. The resulting mixture promoted efficient glycosylation of scFv13-R4 ${ }^{\mathrm{DQNAT}}$ as observed in Western blots probed with anti-His antibody and hR6 serum (Fig. 4a). In addition to scFv13-R4 ${ }^{\mathrm{DQNAT}}$, we also expressed a different model acceptor protein that was created by grafting a 21 -amino acid sequence from the C. jejuni glycoprotein AcrA ${ }^{34}$, which was further modified with an optimized DQNAT glycosylation site, into a flexible loop of superfolder GFP ( sfGFP $^{217-D Q N A T}$ ). The mixed lysate reaction scheme was able to glycosylate the sfGFP $^{217-D Q N A T}$ acceptor protein with $100 \%$ conversion (Fig. 4a). It is noteworthy that the high conversion observed for both acceptor proteins was achieved in mixed lysates without the need to supplement the reactions with purified OST or organic solventextracted CjLLOs.

Next, we sought to demonstrate that the mixed lysate approach could be used to rapidly prototype the activity of four additional bacterial OSTs. Crude extracts were separately prepared from CLM24 source strains heterologously overexpressing one of the following bacterial OSTs: Campylobacter coli PglB (CcPglB), Desulfovibrio desulfuricans $\mathrm{PglB}$ (DdPglB), Desulfovibrio gigas PglB (DgPglB), or Desulfovibrio vulgaris PglB (DvPglB). The resulting extracts were selectively enriched with full-length OST proteins at levels that were comparable to $C j \mathrm{PglB}$ (Supplementary Fig. 3a). Each OST extract was mixed with the CjLLO-enriched extract and then supplemented with plasmid DNA encoding sfGFP $^{217-D Q N A T}$ or a modified version of this target protein where the residue in the -2 position of the acceptor sequon was mutated to alanine. Upon completion of CFGpS reactions, the expression and glycosylation status of sfGFP $217-\mathrm{DQNAT}$ and 

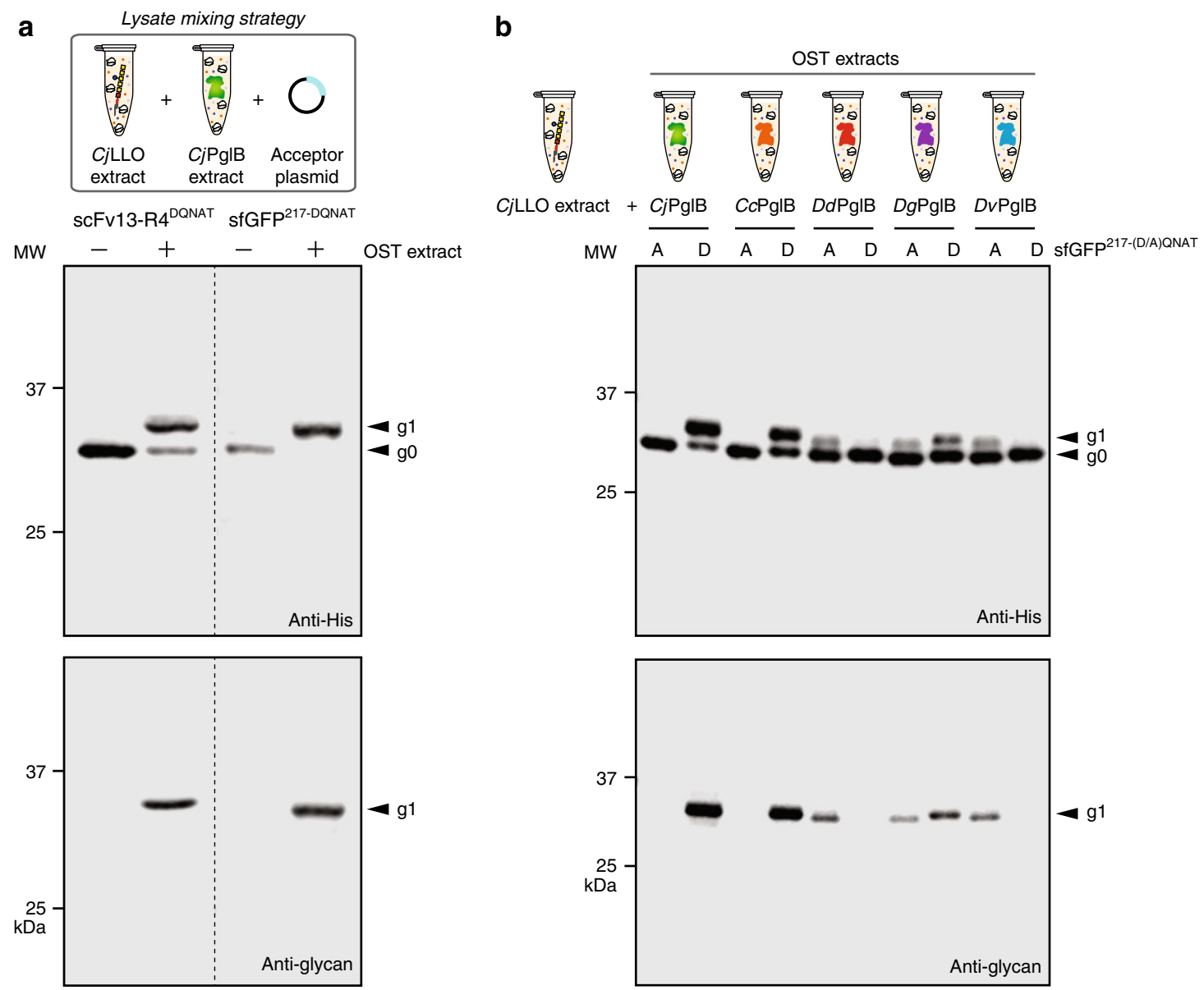

Fig. 4 Mixing of CFGpS extracts enables rapid prototyping of different OST enzymes. a Western blot analysis of CFGpS reactions performed using lysate mixing strategy whereby CjLLO lysate derived from CLM24 cells carrying pMW07-pg| $\triangle \mathrm{B}$ was mixed with CjPg|B lysate derived from CLM24 cells carrying pSF-CjPgIB, and the resulting CFGpS mixture was primed with plasmid DNA encoding either scFv13-R4DQNAT or sfGFP217-DQNAT. b Western blot analysis of CFGpS reactions performed using CjLLO lysate mixed with extract derived from CLM24 cells carrying a pSF plasmid encoding one of the following OSTs: CjPg|B, CcPg|B, DdPg|B, DgPg|B, or DvPg|B. Mixed lysates were primed with plasmid DNA encoding either sfGFP217-DQNAT (D) or sfGFP217-AQNAT (A). Blots were probed with anti-His antibody to detect the acceptor proteins (top panels) and hR6 serum against the C. jejuni glycan (bottom panels). Arrows denote aglycosylated ( $\mathrm{g} 0$ ) and singly glycosylated (g1) forms of the acceptor proteins. Molecular weight (MW) markers are indicated at left. Results are representative of at least three biological replicates

sfGFP $^{217-A Q N A T}$ was followed by western blot analysis, which revealed information about the sequon preferences for these homologous enzymes. For example, the mixed lysate containing $C c$ PglB was observed to efficiently glycosylate sfGFP $217-D Q N A T$ but not sfGFP $217-A Q N A T$ (Fig. 4b). This activity profile for $C c P g l B$ was identical to that observed for $\mathrm{Cj} P g l B$, which was not surprising based on its high sequence similarity $(\sim 81 \%)$ to CjPglB. In contrast, lysate mixtures containing OSTs from Desulfovibrio sp., which have low sequence identity ( 15-20\%) to $\mathrm{Cj} \mathrm{PglB}$, showed more relaxed sequon preferences (Fig. $4 \mathrm{~b}$ ). Specifically, $D g$ PglB-enriched extract mixtures modified both (D/ A)QNAT motifs with nearly equal efficiency while mixed lysates containing DdOST and DvOST preferentially glycosylated the AQNAT sequon.

One-pot extract promotes biosynthesis of diverse glycoproteins. To create a fully integrated CFGpS platform that permits one-pot synthesis of $\mathrm{N}$-glycoproteins without the need for supplementation of either purified OSTs or solvent-extracted LLOs (Fig. 1), we produced crude S30 extract from CLM24 cells heterologously overexpressing $C j \mathrm{PglB}$ and the C. jejuni glycan biosynthesis enzymes. The resulting extract was selectively enriched with both $\mathrm{CjPglB}$ and CjLLOs donor to an extent that was indistinguishable from the separately prepared extracts (Supplementary Fig. 3a and b). Using this extract, CFGpS reactions were performed by addition of plasmid DNA encoding either scFv13$\mathrm{R} 4{ }^{\mathrm{DQNAT}}$ or $\mathrm{sfGFP}^{217-\mathrm{DQNAT}}$. In both cases, $100 \%$ protein glycosylation was achieved without the need for exogenous supplementation of separately prepared glycosylation components (Fig. 5a). Independent extract preparations yielded identical results for both protein substrates, confirming the reproducibility of the CFGpS system (Supplementary Fig. 4a and b). Importantly, the in vitro synthesized scFv13-R4 $4^{\mathrm{DQNAT}}$ and sfGFP $217-\mathrm{DQNAT}$ proteins retained biological activity that was unaffected by $N$ glycan addition (Supplementary Figs. 5 and 6). From the activity data, the yield of glycosylated scFv13-R4 DQNAT and sfGFP 217 DQNAT proteins produced by the one-pot CFGpS system was determined to be $\sim 20$ and $\sim 10 \mathrm{mg} \mathrm{L}^{-1}$, respectively.

To determine whether human glycoproteins could be similarly produced in our one-pot system, we constructed plasmids for cellfree expression of human erythropoietin (hEPO) glycovariants in which the native sequons at residue N24 (22-AENIT-26), N38 (36-NENIT-40) or N83 (81-LVNSS-85) were individually mutated to the optimal bacterial sequon, DQNAT (Fig. 5b). CFGpS reactions were then initiated by priming the all-in-one extract with plasmid 
a
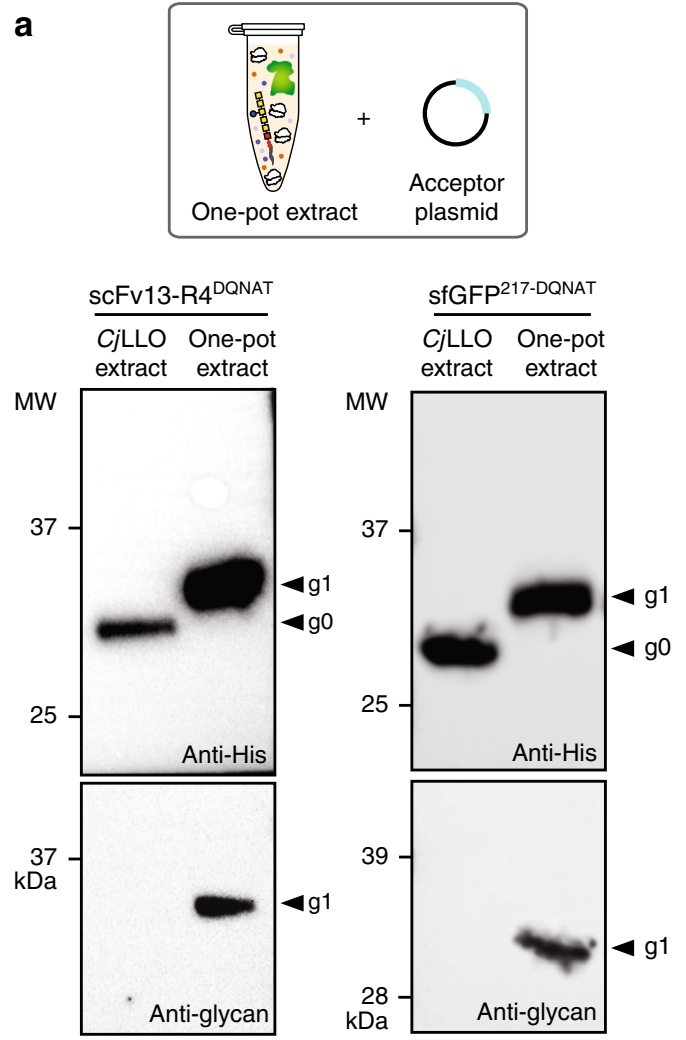

b
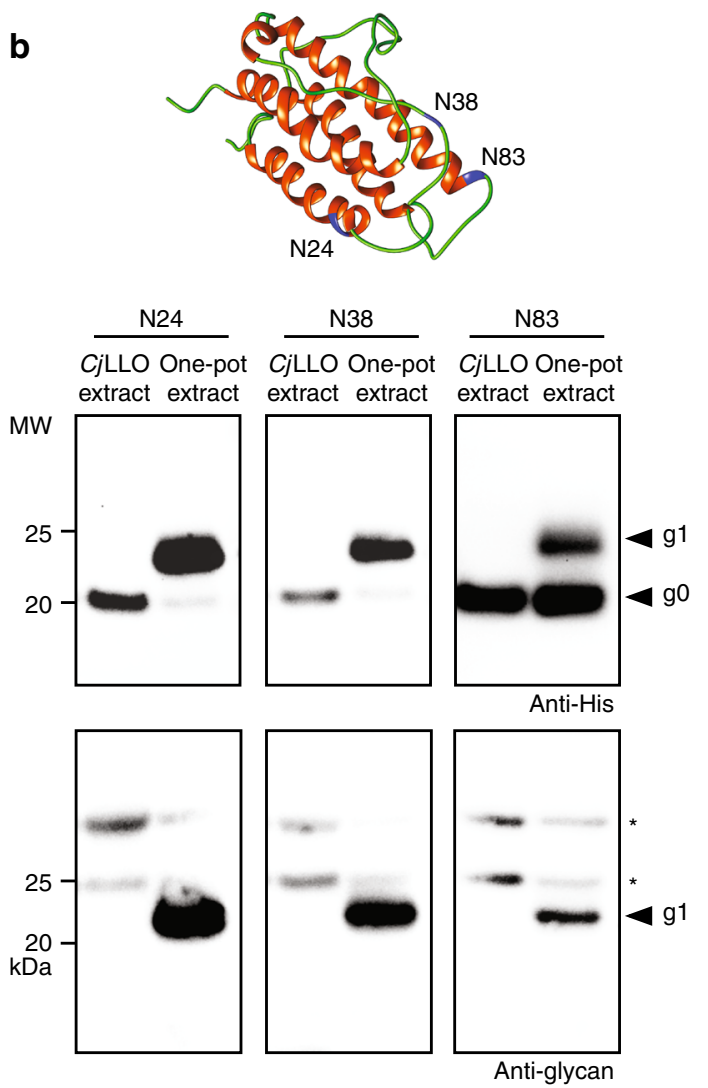

Fig. 5 One-pot CFGpS using extracts selectively enriched with OSTs and LLOs. a Western blot analysis of scFv13-R4 ${ }^{\text {DQNAT }}$ or sfGFP217-DQNAT produced by crude CLM24 extract selectively enriched with (i) CjPgIB from heterologous overexpression from pSF-CjPgIB and (ii) CjLLOs from heterologous overexpression from pMW07-pg| $\triangle \mathrm{B}$. Reactions were primed with plasmid pJL1-scFv13-R4DQNAT or pJL1-sfGFP217-DQNAT. b Ribbon representation of human erythropoietin (PDB code 1BUY) with $\alpha$-helixes and flexible loops colored in red and green, respectively. Glycosylation sites modeled by mutating the native sequons at N24 (22-AENIT-26), N38 (36-NENIT-40), or N83 (81-LVNSS-85) to DQNAT, with asparagine residues in each sequon colored in blue. Image prepared using UCSF Chimera package. ${ }^{68}$ Glycoengineered hEPO variants in which the native sequons at N24 (22-AENIT-26), N38 (36NENIT-40), or N83 (81-LVNSS-85) were individually mutated to an optimal bacterial sequon, DQNAT (shown in blue). Western blot analysis of hEPO glycovariants produced by crude CLM24 extract selectively enriched with (i) CjPgIB from heterologous overexpression from pSF-CjPgIB and (ii) CjLLOs from heterologous overexpression from pMW07-pg| $\Delta$ B. Reactions were primed with plasmid pJL1-hEPO 22-DQNAT-26 (N24), pJL1-hEPO 36-DQNAT-40 (N38), or pJL1-hEPO ${ }^{81-D Q N A T-85}$ (N83) as indicated. All control reactions (lane 1 in each panel) were performed using CjLLO-enriched extracts that lacked CjPgIB. Blots were probed with anti-hexa-histidine antibody (anti-His) to detect the acceptor proteins or hR6 serum (anti-glycan) to detect the N-glycan. Arrows denote aglycosylated ( $\mathrm{g} 0$ ) and singly glycosylated ( $\mathrm{g} 1$ ) forms of the protein targets. Asterisks denote bands corresponding to non-specific serum antibody binding. Molecular weight (MW) markers are indicated at left. Results are representative of at least three biological replicates (see Supplementary Fig. 4 for replicate data)

DNA encoding hEPO 22 -DQNAT-26, hEPO ${ }^{36-D Q N A T-40}$, or hEPO ${ }^{81-}$ DQNAT-85. Western blot analysis revealed clearly detectable glycosylation of each hEPO glycovariant with $100 \%$ glycosylated product for the N24 and N38 sites and $30-40 \%$ for the N83 site (Fig. 5b). As with the model glycoproteins scFv13-R4 ${ }^{\mathrm{DQNAT}}$ and sfGFP $217-D Q N A T$ above, all three glycosylated hEPO variants retained biological activity that was indistinguishable from the activity measured for the corresponding aglycosylated counterparts, with yields in the $\sim 10 \mathrm{mg} \mathrm{L}^{-1}$ range (Supplementary Fig. 7). Collectively, these findings establish that one-pot CFGpS extracts are capable of co-activating protein synthesis and $\mathrm{N}$-glycosylation in a manner that yields efficiently glycosylated proteins including those of human origin.

\section{Discussion}

In this work, we successfully created a technology for one-pot biosynthesis of $N$-linked glycoproteins in the absence of living cells. This was accomplished by uniting cell-free transcription and translation with the necessary reaction components for $\mathrm{N}$-linked protein glycosylation through a process of crude extract enrichment. By preparing OST- and LLO-enriched crude S30 extracts from a glyco-optimized chassis strain, glycosylation-competent lysates were capable of supplying efficiently glycosylated target proteins, with conversion levels at or near $100 \%$ in most instances. The glycoprotein yields obtained for three structurally diverse proteins were in the $10-20 \mathrm{mg} \mathrm{L}^{-1}$ range, which compare favorably to some of the yields reported previously for these proteins in different CFPS kits or in-house generated extracts. For example, Jackson et al. ${ }^{46}$ produced $3.6 \mathrm{mg} \mathrm{L}^{-1}$ of GFP using the PURExpress system, Stech et al. ${ }^{47}$ produced $\sim 12 \mathrm{mg} \mathrm{L}^{-1}$ of an anti-SMAD2 scFv using a CHO cell-derived lysate, Ahn et al. ${ }^{48}$ produced $55 \mathrm{mg} \mathrm{L}^{-1}$ of hEPO using an E. coli-derived S30 lysate, and Gurramkonda et al. ${ }^{31}$ produced $\sim 120 \mathrm{mg} \mathrm{L}^{-1}$ of hEPO using a $\mathrm{CHO}$ cell-derived lysate supplemented with $\mathrm{CHO}$ microsomes.

Furthermore, this work represents the first demonstration of extract enrichment with catalytically active multipass transmembrane enzymes (and their corresponding lipid-linked substrates) without the need for domain truncation or supplementation of extra scaffold molecules ${ }^{49}$, and provides a 
blueprint for other CFPS-based applications beyond glycosylation that involve this important class of proteins. Moreover, the ability of OST- or LLO-enriched crude extracts to co-activate glycosylation partially bypassed the need for costly, labor-intensive preparation of glycosylation components and paved the way for a modular single-pot CFGpS platform in which protein synthesis and $\mathrm{N}$-linked glycosylation were integrated.

A major advantage of the CFGpS system developed here is the level of control it affords over each of the glycosylation components (i.e., catalysts, substrates, and cofactors) in terms of important process variables such as relative concentration, timing of addition, overall reaction time, etc. Likewise, genome engineering of the chassis strain used to supply the extract, such as our recent report enhancing cell-free synthesis containing multiple, identical non-canonical amino acids ${ }^{16}$, makes it possible to eliminate inhibitory substances such as glycosidases that catalyze the undesired hydrolysis of glycosidic linkages. This user-level control provides an opportunity to overcome system bottlenecks that effectively limit glycosylation efficiency as we showed with both the C. jejuni heptasaccharide and the eukaryotic $\mathrm{Man}_{3^{-}}$ $\mathrm{GlcNAc}_{2}$ glycan. Moreover, the open nature of the CFGpS system could be further exploited in the future to introduce components that may otherwise be incompatible with chassis strain expression such as unusual and/or non-natural LLOs that cannot be assembled or flipped in vivo.

An additional advantage of the CFGpS system is that it does not rely on commercial cell-free kits to support protein synthesis. For comparison, the glycoproteins yields obtained here were $\sim 10-20 \mathrm{mg} \mathrm{L}^{-1}$ in reactions costing $\sim \$ 0.01-0.03$ per $\mu \mathrm{L}$ (Supplementary Table 1 and also ref. ${ }^{50}$ ) versus previous kit-based (e.g., Promega L110; NEB ${ }^{\oplus}$ E6800S) glycoprotein yields of $\sim 100 \mathrm{mg} \mathrm{L}$ -134 in reactions costing $\sim \$ 1 \mu \mathrm{L}^{-151}$. As a result, our system can synthesize $\sim 1 \mu \mathrm{g}$ glycoprotein $/ \$$ reagents compared to the previously published approach that can synthesize $\sim 0.1 \mu \mathrm{g}$ glycoprotein/\$ reagents, representing an order of magnitude improvement in relative protein synthesis yields. It is also worth noting that this cost analysis does not take into account the cost of purifying OSTs or extracting LLOs that were used to supplement the commercial kits in our previous work ${ }^{34}$. We anticipate this reduction in cost will encourage adoption of the CFGpS platform.

Perhaps the most important feature of the CFGpS platform is its modularity, which was evidenced by the interchangeability of: (i) OST enzymes from different bacterial species; (ii) engineered LLOs with glycan moieties derived from bacteria and eukaryotes; and (iii) diverse acceptor protein targets including naturally occurring human $\mathrm{N}$-glycoproteins with terminal or internal acceptor sequons. Importantly, enriched extracts could be readily mixed in a manner that enabled screening of an OST panel whose activities in CFGpS were in line with previously reported activities in vivo ${ }^{52}$, thereby validating this lysate mixing strategy as a useful tool for rapid characterization of glycosylation enzyme function and for prototyping glycosylation reactions. In light of this modularity, we envision that lysate enrichment could be further expanded beyond the glycosylation components/substrates tested here. For example, extracts could be heterologously enriched with alternative membrane-bound or soluble OSTs that catalyze $\mathrm{N}$ linked or $O$-linked glycosyl transfer reactions. Such biocatalyst swapping is expected to be relatively straightforward in light of the growing number of prokaryotic and eukaryotic OST enzymes that have been recombinantly expressed in functional conformations and used to promote in vitro glycosylation reactions ${ }^{18,49,52-56}$. Likewise, as newly engineered glycan biosynthesis pathways emerge ${ }^{57}$, these could be readily integrated into the CFGpS platform through heterologous expression of GTs in the chassis strain. The ability to modularly reconfigure and quickly interrogate glycosylation systems in vitro should make the CFGpS technology a useful new addition to the glycoengineering toolkit for increasing our understanding of glycosylation and, in the future, advancing applications of on demand biomolecular manufacturing ${ }^{58-61}$.

\section{Methods}

Bacterial strains and plasmids. The following $E$. coli strains were used in this study: DH5a, BL21(DE3) (Novagen), CLM24, and Origami2(DE3) gmd::kan $\triangle$ waaL. DH5a was used for plasmid cloning and purification. BL21(DE3) was used for expression and purification of the scFv13-R4 DQNAT acceptor protein that was used in all in vitro glycosylation reactions. CLM24 is a glyco-optimized derivative of W3110 that carries a deletion in the gene encoding the WaaL ligase, thus facilitating the accumulation of preassembled glycans on Und-PP ${ }^{36}$. CLM24 was used for purification of the CjOST enzyme, organic solvent-based extraction of all LLO sbearing bacterial glycans, and the source strain for preparing extracts with and without selectively enriched glycosylation components. Origami2(DE3) gmd::kan $\Delta w a a L$ was used for producing $\mathrm{Man}_{3} \mathrm{GlcNAc}_{2}$-bearing LLOs and was generated by sequential mutation with $\mathrm{P} 1$ vir phage transduction using the respective strains from the Keio collection ${ }^{62}$ as donors, which were obtained from the Coli Genetic Stock Center (CGSC). In brief, donor lysate was generated from strain JW3597-1 $(\Delta r f a L 734:: \mathrm{kan})$ and the resulting phage was used to infect Origami2(DE3) target cells. After plating transformants on LB plates containing kanamycin (Kan), successful transductants were selected and their Kan resistance cassettes were removed by transforming with temperature-sensitive plasmid pCP $20^{63}$. The resulting strain, Origami2(DE3) $\Delta w a a L$, was then used for subsequent deletion of the gmd gene according to an identical strategy but using donor strain JW2038-1 ( $\Delta$ gmd751:: kan).

All plasmids used in the study are listed in Supplementary Table 2. Plasmids constructed in this study were made using standard cloning protocols and confirmed by DNA sequencing. These included the following. Plasmid pJL1scFv13-R4 ${ }^{\text {DQNAT }}$ was generated by first PCR amplifying the gene encoding scFv13R4 ${ }^{\text {DQNAT }}$ from pET28a-scFv13-R4(N34L, N77L) ${ }^{\text {DQNAT }}$, where the N34L and N77L mutations were introduced to eliminate putative internal glycosylation sites in scFv13-R $4^{52}$. The resulting PCR product was then ligated between NcoI and SalI restriction sites in plasmid pJL1, a pET-based vector used for CFPS ${ }^{49}$. Plasmid pJL1-sfGFP $217-D Q N A T$ was generated by ligating a commercially-synthesized DNA fragment encoding sfGFP217-DQNAT (Integrated DNA Technologies) into pJL1. This version of sfGFP contains an additional GT insertion after K214, which extends this flexible loop before the final beta sheet ${ }^{64}$. Into this flexible loop, immediately after T216, we grafted a 21 -amino acid sequence containing the C. jejuni AcrA N123 glycosylation site ${ }^{34}$, but with an optimal DQNAT sequon in place of the native AcrA sequon. Similar procedures were used to generate plasmids pJL1-sfGFP $217-A Q N A T$, pJL1-hEPO ${ }^{22-D Q N A T-26}$, pJL1-hEPO ${ }^{36-D Q N A T-40}$, and pJL1-hEPO ${ }^{81-D Q N A T-85}$. In the case of pJL1-hEPO 22 -DQNAT-26, the gene for mature human EPO was designed such that the native sequon at N24 was changed from 22-AENIT-26 to an optimal bacterial sequon, DQNAT. Identical cloning strategies were carried out to separately introduce optimal DQNAT motifs in place of the native hEPO sequons 36-NENIT-40 and 81-LVNSS-85. Recombinant expression of the E. coli O9 primer-adaptor glycan $\left(\mathrm{Man}_{3} \mathrm{GlcNAc}_{\mathrm{C}}\right.$ on Und-PP was achieved by cloning the genes encoding the $\mathrm{WbdB}$ and $\mathrm{WbdC}$ mannosyltransferase enzymes derived from E. coli ATCC31616 for assembling the glycan, and RfbK and RfbM, also derived from E. coli ATCC 31616 for increasing the pool of available GDP-mannose, in E. coli MG1655. Plasmid pConYCGmCB was constructed by isothermal Gibson assembly and encodes an artificial operon comprised of: (i) the yeast glycosyltransferases Alg13, Alg14, Alg1, and Alg2 for $\mathrm{Man}_{3} \mathrm{GlcNAc}_{2}$ glycan biosynthesis $^{12}$ and (ii) the E. coli enzymes phosphomannomutase (ManB) and mannose-1-phosphate guanylyltransferase (ManC), which together increase availability of GDP-mannose substrates for the Alg1 and Alg2 enzymes.

Protein expression and purification. Purification of $C j \mathrm{PglB}$ was performed according to a previously described protocol ${ }^{34}$. Briefly, a single colony of $E$. coli CLM24 carrying plasmid pSN18 $8^{65}$ was grown overnight at $37^{\circ} \mathrm{C}$ in $50 \mathrm{~mL}$ of LuriaBertani (LB; $10 \mathrm{~g} \mathrm{~L}^{-1}$ tryptone, $5 \mathrm{~g} \mathrm{~L}^{-1}$ yeast extract, $5 \mathrm{~g} \mathrm{~L}^{-1} \mathrm{NaCl}, \mathrm{pH} 7.2$ ) supplemented with ampicillin (Amp) and $0.2 \%(\mathrm{w} / \mathrm{v} \%)$ D-glucose. Overnight cells were subcultured into $1 \mathrm{~L}$ of fresh terrific broth (TB; $12 \mathrm{~g} \mathrm{~L}^{-1}$ tryptone, $24 \mathrm{~g} \mathrm{~L}^{-1}$ yeast extract, $0.4 \%$ (v/v\%) glycerol, $10 \%$ (v/v\%) $0.17 \mathrm{M} \mathrm{KH}_{2} \mathrm{PO}_{4} / 0.72 \mathrm{M} \mathrm{K}_{2} \mathrm{HPO}_{4}$ phosphate buffer), supplemented with Amp and grown until the absorbance at $600 \mathrm{~nm}\left(\mathrm{Abs}_{600}\right)$ reached a value of $\sim 0.7$. The incubation temperature was adjusted to $16^{\circ} \mathrm{C}$, after which protein expression was induced by the addition of L-arabinose to a final concentration of $0.02 \%(\mathrm{w} / \mathrm{v} \%)$. Protein expression was allowed to proceed for $20 \mathrm{~h}$ at $16^{\circ} \mathrm{C}$. Cells were harvested by centrifugation and then disrupted using a homogenizer (Avestin C5 EmulsiFlex). The lysate was centrifuged to remove cell debris and the supernatant was ultracentrifuged $(100,000 \times g)$ for $2 \mathrm{~h}$ at $4{ }^{\circ} \mathrm{C}$. The resulting pellet containing the membrane fraction was fully resuspended with a Potter-Elvehjem tissue homogenizer in buffer containing $50 \mathrm{mM}$ HEPES, $250 \mathrm{mM} \mathrm{NaCl}, 10 \%(\mathrm{v} / \mathrm{v} \%)$ glycerol, and $1 \%(\mathrm{w} / \mathrm{v} \%) n$-dodecyl- $\beta$-D-maltoside (DDM) at $\mathrm{pH}$ 7.5. The suspension was incubated at room temperature for $1 \mathrm{~h}$ to facilitate detergent solubilization of $\mathrm{Cj}$ PglB from native $E$. coli lipids, which were 
removed by subsequent ultracentrifugation $(100,000 \times g)$ for $1 \mathrm{~h}$ at $4{ }^{\circ} \mathrm{C}$. The supernatant containing DDM-solubilized CjPglB was purified using Ni-NTA resin (Thermo) according to manufacturer's specification with the exception that al buffers were supplemented with $1 \%(\mathrm{w} / \mathrm{v} \%)$ DDM. The elution fraction from NiNTA purification was then subjected to size exclusion chromatography (SEC) using an ÄKTA Explorer FPLC system (GE Healthcare) with Superdex 200 10/300 GL column. Purified protein was stored at a final concentration of $1-2 \mathrm{mg} \mathrm{mL}^{-1}$ in OST storage buffer (50 mM HEPES, $100 \mathrm{mM} \mathrm{NaCl}, 5 \%$ (v/v\%) glycerol, $0.01 \%$ (w/v\%) DDM, pH 7.5) at $4{ }^{\circ} \mathrm{C}$. Glycerol concentration in the sample was adjusted to $20 \%$ (v/v\%) for long-term storage at $-80^{\circ} \mathrm{C}$

Purification of acceptor protein scFv13-R4 $4^{\mathrm{DQNAT}}$ was carried out as described previously ${ }^{52}$. Briefly, E. coli strain BL21(DE3) carrying plasmid pET28a-scFv13-R4 $(\mathrm{N} 34 \mathrm{~L}, \mathrm{~N} 77 \mathrm{~L})^{\mathrm{DQNAT}}$ was grown in $1 \mathrm{~L}$ of TB supplied with kanamycin. The culture was incubated at $37^{\circ} \mathrm{C}$ until $\mathrm{Abs}_{600}$ reached $\sim 0.7$, at which point protein expression was induced by addition of isopropyl $\beta$-D-1-thiogalactopyranoside (IPTG) to a final concentration of $0.1 \mathrm{mM}$. Protein expression was allowed to proceed for $20 \mathrm{~h}$ at $25^{\circ} \mathrm{C}$. Cells were harvested and disrupted identically as described above. The scFv13-R4 ${ }_{\text {DQNAT }}$ protein was purified using Ni-NTA resin followed by SEC according to manufacturer's protocols. Protein was stored at a final concentration of $1-2 \mathrm{mg} \mathrm{mL}^{-1}$ in storage buffer (50 mM HEPES, $250 \mathrm{mM} \mathrm{NaCl}, 1 \mathrm{mM}$ EDTA, $\mathrm{pH} 7.5)$ at $4^{\circ} \mathrm{C}$

Extraction of LLOs. The protocol for organic solvent extraction of LLOs from E. coli membranes was adapted from a previously described protocol ${ }^{34,66}$. In most cases, a single colony of strain CLM24 carrying a plasmid for target glycan biosynthesis (Supplementary Table 2) was grown overnight in LB media. The notable exceptions were LLOs bearing the $W$. succinogenes $N$-glycan (WsLLOs), which were produced using DH5a cells carrying the pEpiFOS-5pgl5 fosmid (kindly provided by Dr. Markus Aebi), and LLO sbearing $\mathrm{Man}_{3} \mathrm{GlcNAc}_{2}$, which were produced using Origami2(DE3) gmd::kan $\Delta$ waaL cells carrying plasmid pConYCGmCB. Overnight cells were subcultured into $1 \mathrm{~L}$ of TB supplemented with an appropriate antibiotic and grown until the $\mathrm{Abs}_{600}$ reached $\sim 0.7$. The incubation temperature was adjusted to $30^{\circ} \mathrm{C}$ for biosynthesis of all glycans except for $\mathrm{Man}_{3} \mathrm{GlcNAc}_{2}$, which was adjusted to $16^{\circ} \mathrm{C}$. For plasmid pMW07-pgl $\Delta \mathrm{B}$, protein expression was induced with $\mathrm{L}$-arabinose at a final concentration of $0.2 \%(\mathrm{w} / \mathrm{v} \%)$ while for fosmid pEpiFOS-5pgl5 induction was with isopropyl $\beta$-D-1-thiogalactopyranoside (IPTG) at a final concentration of $1 \mathrm{mM}$. All other plasmids involved constitutive promoters and thus did not require chemical inducers. After $16 \mathrm{~h}$, cells were harvested by centrifugation and cell pellets were lyophilized to complete dryness at $-70^{\circ} \mathrm{C}$. For extraction of CjLLOs, native and engineered ClLLOs, E. coli O9 primer-adaptor LLOs, and WsLLOs, the lyophilisates were suspended in 10:20:3 volumetric ratio of $\mathrm{CHCl}_{3}: \mathrm{CH}_{3} \mathrm{OH}: \mathrm{H}_{2} \mathrm{O}$ solution and incubated at room temperature for $15 \mathrm{~min}$ to facilitate extraction of LLOs. For extraction of LLO sbearing $\mathrm{Man}_{3} \mathrm{GlcNAc}_{2}$ glycan, lyophilisate was successively suspended in 10:20 (v/v\%) $\mathrm{CHCl}_{3}: \mathrm{CH}_{3} \mathrm{OH}$ solution, water, and 10:20:3 $\mathrm{CHCl}_{3}: \mathrm{CH}_{3} \mathrm{OH}: \mathrm{H}_{2} \mathrm{O}$ solution with $15 \mathrm{~min}$ of incubation at room temperature between each step. In each case, the final suspension was centrifuged $(4000 \times g)$ for $15 \mathrm{~min}$, after which the organic layer (bottom layer) was collected and dried with a vacuum concentrator followed by lyophilization. Lyophilisates containing active LLOs were resuspended in cell-free glycosylation buffer ( $10 \mathrm{mM}$ HEPES, $\mathrm{pH} 7.5,10 \mathrm{mM} \mathrm{MnCl}_{2}$, and $0.1 \%$ (w/v\%) DDM) and stored at $4{ }^{\circ} \mathrm{C}$.

Preparation of crude S30 extracts. CLM24 source strains were grown in $2 \times$ YTPG $\left(10 \mathrm{~g} \mathrm{~L}^{-1}\right.$ yeast extract, $16 \mathrm{~g} \mathrm{~L}^{-1}$ tryptone, $5 \mathrm{~g} \mathrm{~L}^{-1} \mathrm{NaCl}, 7 \mathrm{~g} \mathrm{~L}^{-1} \mathrm{~K}_{2} \mathrm{HPO}_{4}$, $3 \mathrm{~g} \mathrm{~L}^{-1} \mathrm{KH}_{2} \mathrm{PO}_{4}, 18 \mathrm{~g} \mathrm{~L}^{-1}$ glucose, $\mathrm{pH}$ 7.2) until the $\mathrm{Abs}_{600}$ reached $\sim 3$. To generate OST-enriched extract, CLM24 carrying plasmid pSF-CjPglB, pSF-CcPglB, pSF-DdPglB, pSF- $D g$ PglB, or pSF- $D v$ PglB $^{52}$ was used as the source strain. To generate LLO-enriched extract, CLM24 carrying plasmid pMW07-pgl $\Delta \mathrm{B}$ was used as the source strain. To generate one-pot extract containing both OST and LLOs, CLM24 carrying pMW07-pgl $\triangle \mathrm{B}$ and pSF-CjOST was used as the source strain. As needed, the expression of glycosylation components was induced with L-arabinose at final concentration of $0.02 \%(\mathrm{w} / \mathrm{v} \%)$. After induction, protein expression was allowed to proceed at $30^{\circ} \mathrm{C}$ to a density of $\mathrm{OD}_{600} \sim 3$, at which point cells were harvested by centrifugation $(5000 \times g)$ at $4{ }^{\circ} \mathrm{C}$ for $15 \mathrm{~min}$. All subsequent steps were carried out at $4{ }^{\circ} \mathrm{C}$ unless otherwise stated. Pelleted cells were washed three times in S30 buffer $(10 \mathrm{mM}$ tris acetate, $14 \mathrm{mM}$ magnesium acetate, $60 \mathrm{mM}$ potassium acetate, $\mathrm{pH} 8.2$ ). After the last wash, cells were pelleted at $7000 \times \mathrm{g}$ for $10 \mathrm{~min}$ and flash-frozen on liquid nitrogen. To make lysate, cells were thawed and resuspended to homogeneity in $1 \mathrm{~mL}$ of S30 buffer per $1 \mathrm{~g}$ of wet cell mass. Cells were disrupted using an Avestin EmulsiFlex-B15 high-pressure homogenizer at 20,000-25,000 psi with a single passage. The lysate was then centrifuged twice at $30,000 \times g$ for $30 \mathrm{~min}$ to remove cell debris. Supernatant was transferred to a new vessel and incubated with $250 \mathrm{rpm}$ shaking at $37^{\circ} \mathrm{C}$ for 60 min to degrade endogenous mRNA transcripts and disrupt existing polysome complexes in the lysate. Following centrifugation $(15,000 \times g)$ for $15 \mathrm{~min}$ at $4{ }^{\circ} \mathrm{C}$, supernatant was collected, aliquoted, flash-frozen in liquid nitrogen, and stored at $-80^{\circ} \mathrm{C}$. S30 extract was active for about three freeze-thaw cycles and contained $\sim 40 \mathrm{~g} \mathrm{~L}^{-1}$ total protein as measured by Bradford assay.
Cell-free glycoprotein synthesis. For in vitro glycosylation of purified acceptor protein, reactions were carried out in a $50 \mu \mathrm{L}$ volume containing $3 \mu \mathrm{g}$ of scFvi3$\mathrm{R} 4^{\mathrm{DQNAT}}, 2 \mu \mathrm{g}$ of purified CjPglB, and $5 \mu \mathrm{g}$ extracted LLOs (in the case of $\mathrm{Man}_{3}$ $\mathrm{GlcNAc}_{2}$ LLOs, $20 \mu \mathrm{g}$ was used) in in vitro glycosylation buffer (10 mM HEPES, pH $7.5,10 \mathrm{mM} \mathrm{MnCl}_{2}$, and $0.1 \%$ (w/v\%) DDM). The reaction mixture was incubated at $30^{\circ} \mathrm{C}$ for $16 \mathrm{~h}$. For crude extract-based expression of glycoproteins, a two-phase scheme was implemented. In the first phase, protein synthesis was carried out with a modified PANOx-SP system ${ }^{67}$. Specifically, $1.5 \mathrm{~mL}$ microcentrifuge tubes were charged with $15-\mu \mathrm{L}$ reactions containing 200 ng plasmid DNA, 30\% (v/v\%) S30 extract and the following: $12 \mathrm{mM}$ magnesium glutamate, $10 \mathrm{mM}$ ammonium glutamate, $130 \mathrm{mM}$ potassium glutamate, $1.2 \mathrm{mM}$ adenosine triphosphate (ATP), $0.85 \mathrm{mM}$ guanosine triphosphate (GTP), $0.85 \mathrm{mM}$ uridine triphosphate (UTP), $0.85 \mathrm{mM}$ cytidine triphosphate (CTP), $0.034 \mathrm{mg} \mathrm{mL}^{-1}$ folinic acid, $0.171 \mathrm{mg} \mathrm{mL}^{-1}$ E. coli tRNA (Roche), $2 \mathrm{mM}$ each of 20 amino acids, $30 \mathrm{mM}$ phosphoenolpyruvate (PEP, Roche), $0.4 \mathrm{mM}$ nicotinamide adenine dinucleotide (NAD), $0.27 \mathrm{mM}$ coenzyme-A (CoA), $4 \mathrm{mM}$ oxalic acid, $1 \mathrm{mM}$ putrescine, $1.5 \mathrm{mM}$ spermidine, and $57 \mathrm{mM}$ HEPES. For scFv13-R4 ${ }^{\text {DQNAT }}$, hEPO $^{22-D Q N A T-26}$, hEPO $^{36-D Q N A T-40}$, and hEPO $^{81-D Q N A T 85}$, this phase was carried out at $30^{\circ} \mathrm{C}$ for $4 \mathrm{~h}$ under oxidizing conditions while for sfGFP $217-$ DQNAT and sfGFP 217 -AQNAT this phase was carried out at $30^{\circ} \mathrm{C}$ for $5 \mathrm{~min}$ under reducing conditions. For oxidizing conditions, extract was pre-conditioned with $750 \mu \mathrm{M}$ iodoacetamide in the dark at room temperature for $30 \mathrm{~min}$ and the reaction mix was supplied with $200 \mathrm{mM}$ glutathione at a 3:1 ratio between oxidized and reduced forms. The active sfGFP yields from cell-free reactions were quantified by measuring fluorescence in-lysate and converting into concentration using a standard curve as previously described ${ }^{39}$. In the second phase, protein glycosylation was initiated by the addition of $\mathrm{MnCl}_{2}$ and $\mathrm{DDM}$ at a final concentration of $10 \mathrm{mM}$ and $0.1 \%(\mathrm{w} / \mathrm{v} \%)$, respectively, and allowed to proceed at $30^{\circ} \mathrm{C}$ for $16 \mathrm{~h}$. As needed, reactions were supplemented with $2 \mu \mathrm{g}$ of purified CjPglB (i.e., for CFGpS with LLOenriched extracts) or $5 \mu$ g solvent-extracted CjLLOs (i.e., for CFGpS with OSTenriched extracts). All reactions were stopped by adding Laemmli sample buffer containing $5 \%$ ME, after which samples were boiled at $100{ }^{\circ} \mathrm{C}$ for $15 \mathrm{~min}$ and analyzed by SDS-PAGE and western blotting.

Western blot analysis. Samples containing $0.5 \mu \mathrm{g}$ of acceptor protein were loaded into SDS-PAGE gels. Following electrophoretic separation, proteins were transferred from gels onto Immobilon-P polyvinylidene difluoride (PVDF) membranes $(0.45 \mu \mathrm{m})$ according to manufacturer's protocol. Membranes were washed twice with TBS buffer $\left(80 \mathrm{~g} \mathrm{~L}^{-1} \mathrm{NaCl}, 20 \mathrm{~g} \mathrm{~L}^{-1} \mathrm{KCl}\right.$, and $30 \mathrm{~g} \mathrm{~L}^{-1}$ Tris-base) followed by incubation for $1 \mathrm{~h}$ in blocking solution $\left(50 \mathrm{~g} \mathrm{~L}^{-1}\right.$ non-fat milk in TBST (TBS supplied with $0.05 \%(\mathrm{v} / \mathrm{v} \%)$ Tween-20)). After blocking, membranes were washed 4 times with TBST with 10 min incubation between each wash. A first membrane was probed with 6xHis-polyclonal antibody (Abcam, ab137839, 1:7500) that specifically recognizes hexahistidine epitope tags while a second replicate membrane was probed with one of the following: hR6 $(1: 10,000)$ serum from rabbit that recognizes the native C. jejuni and C. lari glycan as well as engineered C. lari glycan or ConAHRP (Sigma, L6397, 1:2500) that recognizes $\mathrm{Man}_{3}$ GlcNac and $\mathrm{Man}_{3} \mathrm{GlcNAc}_{2}$ Probing of membranes was performed for at least $1 \mathrm{~h}$ with shaking at room temperature, after which membranes were washed with TBST in the same manner as described above. For development, membranes were incubated briefly at room temperature with Western ECL substrate (BioRad) and imaged using a ChemiDocTM XRS+System. OST enzymes enriched in extracts were detected by an identical SDS-PAGE procedure followed by Western blot analysis with a polyclonal antibody specific to the FLAG epitope tag (Abcam, ab49763, 1:7500). The glycan component of LLOs enriched in extracts was detected by directly spotting $10 \mu \mathrm{L}$ of extracts onto nitrocellulose membranes followed by detection with hR6 serum. Uncropped immunoblot images are shown in Supplementary Fig. 8.

MS analysis. Approximately $2 \mu \mathrm{g}$ of $\mathrm{scFv} 13-\mathrm{R} 4^{\mathrm{DQNAT}}$ protein in solution was denatured with $6 \mathrm{M}$ urea, reduced with $10 \mathrm{mM}$ DTT, incubated at $34^{\circ} \mathrm{C}$ for $1 \mathrm{~h}$, then alkylated with $58 \mathrm{mM}$ iodoacetamide for $45 \mathrm{~min}$ in the dark at room temperature and quenched by final $36 \mathrm{mM}$ DTT. The solution was then diluted with $50 \mathrm{mM}$ ammonium bicarbonate $(\mathrm{pH} 8.0)$ to a final buffer concentration of $1 \mathrm{M}$ urea prior to trypsin digestion. Sample was digested with $0.2 \mu \mathrm{g}$ of trypsin for $18 \mathrm{~h}$ at $37^{\circ} \mathrm{C}$. The digestion was stopped by addition of TFA to a final $\mathrm{pH} 2.2-2.5$. The samples were then desalted with SOLA HRP SPE Cartridge (ThermoFisher Scientific). The cartridges were conditioned with $1 \times 0.5 \mathrm{~mL} 90 \%$ methanol, $0.1 \%$ trifluoroacetic acid (TFA) and equilibrated with $2 \times 0.5 \mathrm{~mL} 0.1 \%(\mathrm{v} / \mathrm{v} \%)$ TFA. The samples were diluted $1: 1$ with $0.2 \%(\mathrm{v} / \mathrm{v} \%)$ TFA and run slowly through the cartridges. After washing with $2 \times 0.5 \mathrm{~mL}$ of equilibration solution, peptides were eluted by $1 \times 0.5 \mathrm{~mL}$ of $50 \%(\mathrm{v} / \mathrm{v} \%)$ acetonitrile $(\mathrm{ACN}), 0.1 \%(\mathrm{v} / \mathrm{v} \%)$ TFA and dried in a speed vacuum centrifuge.

The nanoLC-MS/MS analysis was carried out using UltiMate3000 RSLCnano (Dionex) coupled to an Orbitrap Fusion (ThermoFisher Scientific) mass spectrometer equipped with a nanospray Flex Ion Source. Each sample was reconstituted in $22 \mu \mathrm{L}$ of $0.5 \%(\mathrm{w} / \mathrm{v} \%)$ FA and $10 \mu \mathrm{L}$ was loaded onto an Acclaim PepMap $100 \mathrm{C} 18$ trap column $(5 \mu \mathrm{m}, 100 \mu \mathrm{m} \times 20 \mathrm{~mm}, 100 \AA$, ThermoFisher Scientific) with nanoViper Fittings at $20 \mu \mathrm{L} \mathrm{min}{ }^{-1}$ of $0.5 \%$ FA for on-line desalting. After $2 \mathrm{~min}$, the valve switched to allow peptides to be separated on an Acclaim PepMap C18 nano column ( $3 \mu \mathrm{m}, 75 \mu \mathrm{m} \times 25 \mathrm{~cm}$, ThermoFisher Scientific), in a 90 min gradient of 5 to $23 \%$ to $35 \% \mathrm{~B}$ at $300 \mathrm{~nL} \mathrm{m^{-1 }}$ ( 3 to 73 to $93 \mathrm{~min}$, respectively), followed by a 9-min ramping 
to $90 \%$ B, a 9-min hold at $90 \%$ B and quick switch to $5 \%$ B in $1 \mathrm{~min}$. The column was re-equilibrated with $5 \%$ B for 20 min prior to the next run. The Orbitrap Fusion was operating in positive ion mode with nanospray voltage set at $1.7 \mathrm{kV}$ and source temperature at $275^{\circ} \mathrm{C}$. External calibration for FT, IT and quadrupole mass analyzers was performed prior to the analysis. The Orbitrap full MS survey scan $(\mathrm{m} / \mathrm{z}$ 400-1800) was followed by Top $3 \mathrm{~s}$ data-dependent Higher Collision dissociation product ion triggered ETD (HCD-pd-ETD) MS/MS scans for precursor peptides with 2-7 charges above a threshold ion count of 50,000 with normalized collision energy of $32 \%$. MS survey scans were acquired at a resolving power of 120,000 (FWHM at $\mathrm{m} / \mathrm{z}$ 200), with Automatic Gin Control (AGC) $=2 \mathrm{e} 5$ and maximum injection time (Max IT) $=50 \mathrm{~ms}$, and HCD MS/MS scans at a resolution of 30,000 with AGC $=5 \mathrm{e} 4$, Max IT $=60 \mathrm{~ms}$ and with $\mathrm{Q}$ isolation window $(\mathrm{m} / z)$ at 3 for the mass range $\mathrm{m} / z$ 105-2000. Dynamic exclusion parameters were set at 1 within $60 \mathrm{~s}$ exclusion duration with $\pm 10 \mathrm{ppm}$ exclusion mass width. Product Ion trigger list consisted of peaks at 204.0867 $\mathrm{Da}$ (HexNAc oxonium ion), $138.0545 \mathrm{Da}$ (HexNAc fragment), and $366.1396 \mathrm{Da}$ (HexHexNAc oxonium ions). If one of the HCD product ions in the list was detected, two charge-dependent ETD MS/MS scans (EThcD) with HCD supplemental activation (SA) on the same precursor ion were triggered and collected in a linear ion trap. For doubly charged precursors, the ETD reaction time as set $150 \mathrm{~ms}$ and the SA energy was set at $30 \%$, while the same parameters at $125 \mathrm{~ms}$ and $20 \%$, respectively, were used for higher charged precursors. For both ion triggered scans, fluoranthene ETD reagent target was set at 2e5, AGC target at 1e4, Max IT at $105 \mathrm{~ms}$ and isolation window at 3. All data were acquired using Xcalibur 3.0 operation software and Orbitrap Fusion Tune Application v. 2.1 (ThermoFisher Scientific).

All MS and MS/MS raw spectra from each sample were searched using Byonics v. 2.8.2 (Protein Metrics) using the $E$ coli protein database with added scFv13$\mathrm{R} 4{ }^{\mathrm{DQNAT}}$ protein target sequence. The peptide search parameters were as follows: two missed cleavage for full trypsin digestion with fixed carbamidomethyl modification of cysteine, variable modifications of methionine oxidation, and deamidation on asparagine/glutamine residues. The peptide mass tolerance was $10 \mathrm{ppm}$ and fragment mass tolerance values for $\mathrm{HCD}$ and $\mathrm{ETh} \mathrm{CD}$ spectra were 0.05 and $0.6 \mathrm{Da}$, respectively. Both the maximum number of common and rare modifications were set at two. The glycan search was performed against a list of 309 mammalian $N$-linked glycans in Byonic software. Identified peptides were filtered for maximum $2 \%$ FDR. The software exported the results of the search to a spreadsheet.

GFP fluorescence activity. The activity of cell-free-derived sfGFP was determined using an in-lysate fluorescence analysis as described previously ${ }^{39}$. Briefly, $2 \mu \mathrm{L}$ of cell-free synthesized glycosylated sfGFP reaction was diluted into $48 \mu \mathrm{L}$ of nanopure water. The solution was then placed in a Costar 96-well black assay plate (Corning). Excitation and emission wavelengths for sfGFP fluorescence were 485 and $528 \mathrm{~nm}$, respectively.

Enzyme-linked immunosorbent analysis (ELISA). Costar 96-well ELISA plates (Corning) were coated overnight at $4{ }^{\circ} \mathrm{C}$ with $50 \mu \mathrm{l}$ of $1 \mathrm{mg} \mathrm{mL}^{-1}$ E. coli $\beta$-gal (Sigma-Aldrich) in $0.05 \mathrm{M}$ sodium carbonate buffer ( $\mathrm{pH}$ 9.6). After blocking with $5 \%(\mathrm{w} / \mathrm{v} \%)$ bovine serum albumin (BSA) in PBS for $3 \mathrm{~h}$ at room temperature, the plates were washed four times with PBST buffer (PBS, $0.05 \%$ (v/v\%) Tween-20, $0.3 \%(\mathrm{w} / \mathrm{v} \%) \mathrm{BSA}$ ) and incubated with serially diluted purified scFv13-R4 samples or soluble fractions of CFGpS lysates for $1 \mathrm{~h}$ at room temperature. Samples were quantified by the Bradford assay and an equivalent amount of total protein was applied to the plate. After washing four times with the same buffer, anti-6x-His-HRP conjugated rabbit polyclonal antibody (Abcam) in 3\% PBST was added to each well for $1 \mathrm{~h}$. Plates were washed and developed using standard protocols.

In vitro cell proliferation assay. Human erythroleukemia TF- 1 cells (Sigma) that require granulocyte-macrophage colony-stimulating factor (GM-CSF), interleukin 3 (IL-3), or hEPO for growth and survival were used. Cells were maintained in RPMI-1640 media supplemented with $10 \% \mathrm{FBS}, 50 \mathrm{U} \mathrm{mL}^{-1}$ penicillin, $50 \mathrm{mg} \mathrm{mL}^{-1}$ streptomycin, $2 \mathrm{mM}$ glutamine, and $2 \mathrm{ng} \mathrm{mL}^{-1} \mathrm{GM}-\mathrm{CSF}$ at $37^{\circ} \mathrm{C}$ in a humidified atmosphere containing 5\% $\mathrm{CO}_{2}$. After $16 \mathrm{~h}$ incubation in RPMI-1640 media without GM-CSF, cells were counted, harvested, and resuspended in fresh media. $5 \times 10^{3}$ TF- 1 cells per well were seeded in a 96-well assay plate, and EPO standards or samples were added to final desired concentrations to each well. Cells were incubated with for $6 \mathrm{~h}$ in humid incubator before adding alamarBlue ${ }^{\circ}$. After $12 \mathrm{~h}$, fluorescence signal was measured at $560 \mathrm{~nm} / 590 \mathrm{~nm}$ excitation/emission wavelength.

Data availability. All data generated during the study are included in this article and its supplementary information files, and are available from the authors upon reasonable request.

Received: 16 October 2017 Accepted: 6 June 2018

Published online: 12 July 2018

\section{References}

1. Helenius, A. \& Aebi, M. Intracellular functions of N-linked glycans. Science 291, 2364-2369 (2001).

2. Imperiali, B. \& O'Connor, S. E. Effect of N-linked glycosylation on glycopeptide and glycoprotein structure. Curr. Opin. Chem. Biol. 3, 643-649 (1999).

3. Hebert, D. N., Lamriben, L., Powers, E. T. \& Kelly, J. W. The intrinsic and extrinsic effects of N-linked glycans on glycoproteostasis. Nat. Chem. Biol. 10, 902-910 (2014).

4. Rudd, P. M., Elliott, T., Cresswell, P., Wilson, I. A. \& Dwek, R. A. Glycosylation and the immune system. Science 291, 2370-2376 (2001).

5. Wolfert, M. A. \& Boons, G. J. Adaptive immune activation: glycosylation does matter. Nat. Chem. Biol. 9, 776-784 (2013).

6. Lanctot, P. M., Gage, F. H. \& Varki, A. P. The glycans of stem cells. Curr Opin. Chem. Biol. 11, 373-380 (2007).

7. Sinclair, A. M. \& Elliott, S. Glycoengineering: the effect of glycosylation on the properties of therapeutic proteins. J. Pharm. Sci. 94, 1626-1635 (2005).

8. Raman, R., Raguram, S., Venkataraman, G., Paulson, J. C. \& Sasisekharan, R. Glycomics: an integrated systems approach to structure-function relationships of glycans. Nat. Methods 2, 817-824 (2005).

9. Rudd, P. M. \& Dwek, R. A. Glycosylation: heterogeneity and the 3D structure of proteins. Crit. Rev. Biochem Mol. Biol. 32, 1-100 (1997).

10. Meuris, L. et al. GlycoDelete engineering of mammalian cells simplifies Nglycosylation of recombinant proteins. Nat. Biotechnol. 32, 485-489 (2014).

11. Hamilton, S. R. et al. Production of complex human glycoproteins in yeast. Science 301, 1244-1246 (2003).

12. Valderrama-Rincon, J. D. et al. An engineered eukaryotic protein glycosylation pathway in Escherichia coli. Nat. Chem. Biol. 8, 434-436 (2012).

13. Carlson, E. D., Gan, R., Hodgman, C. E. \& Jewett, M. C. Cell-free protein synthesis: applications come of age. Biotechnol. Adv. 30, 1185-1194 (2012).

14. Kiga, D. et al. An engineered Escherichia coli tyrosyl-tRNA synthetase for sitespecific incorporation of an unnatural amino acid into proteins in eukaryotic translation and its application in a wheat germ cell-free system. Proc. Natl. Acad. Sci. USA 99, 9715-9720 (2002).

15. Oza, J. P. et al. Robust production of recombinant phosphoproteins using cellfree protein synthesis. Nat. Commun. 6, 8168 (2015).

16. Martin, R. W. et al. Cell-free protein synthesis from genomically recoded bacteria enables multisite incorporation of noncanonical amino acids. Nat. Commun. 9, 1203 (2018).

17. Stapleton, J. A. \& Swartz, J. R. Development of an in vitro compartmentalization screen for high-throughput directed evolution of [FeFe] hydrogenases. PLOS ONE 5, e15275 (2010).

18. Kightlinger, W. et al. Design of glycosylation sites by rapid synthesis and analysis of glycosyltransferases. Nat. Chem. Biol. 14, 627-635 (2018).

19. Albayrak, C. \& Swartz, J. R. Cell-free co-production of an orthogonal transfer RNA activates efficient site-specific non-natural amino acid incorporation. Nucleic. Acids Res. 41, 5949-5963 (2013).

20. Karim, A. S. \& Jewett, M. C. A cell-free framework for rapid biosynthetic pathway prototyping and enzyme discovery. Metab. Eng. 36, 116-126 (2016).

21. Kaiser, L. et al. Efficient cell-free production of olfactory receptors: detergent optimization, structure, and ligand binding analyses. Proc. Natl Acad. Sci. USA 105, 15726-15731 (2008)

22. Dudley, Q. M., Anderson, K. C. \& Jewett, M. C. Cell-free mixing of Escherichia coli crude extracts to prototype and rationally engineer high-titer mevalonate synthesis. ACS Synth. Biol. 5, 1578-1588 (2016).

23. Moore, S. J. et al. Rapid acquisition and model-based analysis of cell-free transcription-translation reactions from nonmodel bacteria. Proc. Natl. Acad. Sci. USA 115, E4340-E4349 (2018).

24. Goshima, N. et al. Human protein factory for converting the transcriptome into an in vitro-expressed proteome. Nat. Methods 5, 1011-1017 (2008)

25. Matsuoka, K., Komori, H., Nose, M., Endo, Y. \& Sawasaki, T. Simple screening method for autoantigen proteins using the N-terminal biotinylated protein library produced by wheat cell-free synthesis. J. Proteome Res 9, 4264-4273 (2010).

26. Tarui, H., Imanishi, S. \& Hara, T. A novel cell-free translation/glycosylation system prepared from insect cells. J. Biosci. Bioeng. 90, 508-514 (2000).

27. Moreno, S. N., Ip, H. S. \& Cross, G. A. An mRNA-dependent in vitro translation system from Trypanosoma brucei. Mol. Biochem. Parasitol. 46, 265-274 (1991).

28. Mikami, S., Kobayashi, T., Yokoyama, S. \& Imataka, H. A hybridoma-based in vitro translation system that efficiently synthesizes glycoproteins. J. Biotechnol. 127, 65-78 (2006).

29. Brodel, A. K. et al. IRES-mediated translation of membrane proteins and glycoproteins in eukaryotic cell-free systems. PLoS ONE 8, e82234 (2013).

30. Shibutani, M., Kim, E., Lazarovici, P., Oshima, M. \& Guroff, G. Preparation of a cell-free translation system from PC12 cell. Neurochem. Res. 21, 801-807 (1996). 
31. Gurramkonda, C. et al. Improving the recombinant human erythropoietin glycosylation using microsome supplementation in $\mathrm{CHO}$ cell-free system. Biotechnol. Bioeng. 115, 1253-1264 (2018).

32. Lingappa, V. R., Lingappa, J. R., Prasad, R., Ebner, K. E. \& Blobel, G. Coupled cell-free synthesis, segregation, and core glycosylation of a secretory protein. Proc. Natl. Acad. Sci. USA 75, 2338-2342 (1978).

33. Rothblatt, J. A. \& Meyer, D. I. Secretion in yeast: reconstitution of the translocation and glycosylation of alpha-factor and invertase in a homologous cell-free system. Cell 44, 619-628 (1986).

34. Guarino, C. \& DeLisa, M. P. A prokaryote-based cell-free translation system that efficiently synthesizes glycoproteins. Glycobiology 22, 596-601 (2012).

35. Weerapana, E. \& Imperiali, B. Asparagine-linked protein glycosylation: from eukaryotic to prokaryotic systems. Glycobiology 16, 91R-101R (2006).

36. Feldman, M. F. et al. Engineering N-linked protein glycosylation with diverse $\mathrm{O}$ antigen lipopolysaccharide structures in Escherichia coli. Proc. Natl. Acad. Sci. USA 102, 3016-3021 (2005).

37. Liu, D. \& Reeves, P. R. Escherichia coli $\mathrm{K} 12$ regains its $\mathrm{O}$ antigen. Microbiology 140(Pt 1), 49-57 (1994).

38. Chen, L. et al. Outer membrane vesicles displaying engineered glycotopes elicit protective antibodies. Proc. Natl. Acad. Sci. USA 113, E3609-E3618 (2016).

39. Kwon, Y. C. \& Jewett, M. C. High-throughput preparation methods of crude extract for robust cell-free protein synthesis. Sci. Rep. 5, 8663 (2015).

40. Schwarz, F. et al. Relaxed acceptor site specificity of bacterial oligosaccharyltransferase in vivo. Glycobiology 21, 45-54 (2011).

41. Schwarz, F. et al. A combined method for producing homogeneous glycoproteins with eukaryotic N-glycosylation. Nat. Chem. Biol. 6, 264-266 (2010).

42. Jervis, A. J. et al. Characterization of the structurally diverse $\mathrm{N}$-linked glycans of Campylobacter species. J. Bacteriol. 194, 2355-2362 (2012).

43. Hagelueken, G. et al. A coiled-coil domain acts as a molecular ruler to regulate $\mathrm{O}$-antigen chain length in lipopolysaccharide. Nat. Struct. Mol. Biol. 22, 50-56 (2015).

44. Srichaisupakit, A., Ohashi, T., Misaki, R. \& Fujiyama, K. Production of initialstage eukaryotic N-glycan and its protein glycosylation in Escherichia coli. J. Biosci. Bioeng. 119, 399-405 (2015).

45. Jewett, M. C., Calhoun, K. A., Voloshin, A., Wuu, J. J. \& Swartz, J. R. An integrated cell-free metabolic platform for protein production and synthetic biology. Mol. Syst. Biol. 4, 220 (2008).

46. Jackson, K., Kanamori, T., Ueda, T. \& Fan, Z. H. Protein synthesis yield increased 72 times in the cell-free PURE system. Integr. Biol. 6, 781-8 (2014).

47. Stech, M. et al. Cell-free synthesis of functional antibodies using a coupled in vitro transcription-translation system based on CHO cell lysates. Sci. Rep. 7, 12030 (2017).

48. Ahn, J. H., Hwang, M. Y., Lee, K. H., Choi, C. Y. \& Kim, D. M. Use of signal sequences as an in situ removable sequence element to stimulate protein synthesis in cell-free extracts. Nucleic. Acids Res. 35, e21 (2007).

49. Schoborg, J. A. et al. A cell-free platform for rapid synthesis and testing of active oligosaccharyltransferases. Biotechnol. Bioeng. 115, 739-750 (2018)

50. Sun, Z. Z. et al. Protocols for implementing an Escherichia coli based TX-TL cell-free expression system for synthetic biology. J. Vis. Exp. 79, e50762 (2013).

51. Hayes, C. Biomolecular Breadboards:Protocols:cost estimate. http://www. openwetware.org/wiki/Biomolecular_Breadboards:Protocols:cost_estimate (Vol. 2017) (2012).

52. Ollis, A. A. et al. Substitute sweeteners: diverse bacterial oligosaccharyltransferases with unique $\mathrm{N}$-glycosylation site preferences. Sci. Rep. 5, 15237 (2015).

53. Ramirez, A. S. et al. Characterization of the single-subunit oligosaccharyltransferase STT3A from Trypanosoma brucei using synthetic peptides and lipid-linked oligosaccharide analogs. Glycobiology 27, 525-535 (2017).

54. Lizak, C., Gerber, S., Numao, S., Aebi, M. \& Locher, K. P. X-ray structure of a bacterial oligosaccharyltransferase. Nature 474, 350-355 (2011)

55. Musumeci, M. A. et al. In vitro activity of Neisseria meningitidis PglL Ooligosaccharyltransferase with diverse synthetic lipid donors and a UDPactivated sugar. J. Biol. Chem. 288, 10578-10587 (2013).

56. Glover, K. J., Weerapana, E., Numao, S. \& Imperiali, B. Chemoenzymatic synthesis of glycopeptides with PglB, a bacterial oligosaccharyl transferase from Campylobacter jejuni. Chem. Biol. 12, 1311-1315 (2005).

57. Merritt, J. H., Ollis, A. A., Fisher, A. C. \& DeLisa, M. P. Glycans-by-design: engineering bacteria for the biosynthesis of complex glycans and glycoconjugates. Biotechnol. Bioeng. 110, 1550-1564 (2013).

58. Pardee, K. et al. Paper-based synthetic gene networks. Cell 159, 940-954 (2014).

59. Salehi, A. S. et al. Cell-free protein synthesis of a cytotoxic cancer therapeutic: onconase production and a just-add-water cell-free system. Biotechnol. J. 11, 274-281 (2016).
60. Pardee, K. et al. Portable, on-demand biomolecular manufacturing. Cell 167, 248.e12-259.e12 (2016).

61. Sullivan, C. J. et al. A cell-free expression and purification process for rapid production of protein biologics. Biotechnol. J. 11, 238-248 (2016).

62. Baba, T. et al. Construction of Escherichia coli K-12 in-frame, single-gene knockout mutants: the Keio collection. Mol. Syst. Biol. 2, 2006 (2006). 0008

63. Datsenko, K. A. \& Wanner, B. L. One-step inactivation of chromosomal gene in Escherichia coli K-12 using PCR products. Proc. Natl. Acad. Sci. USA 97, 6640-6645 (2000)

64. Bundy, B. C. \& Swartz, J. R. Site-specific incorporation of ppropargyloxyphenylalanine in a cell-free environment for direct proteinprotein click conjugation. Bioconjug. Chem. 21, 255-263 (2010).

65. Kowarik, M. et al. N-linked glycosylation of folded proteins by the bacterial oligosaccharyltransferase. Science 314, 1148-1150 (2006).

66. Jaroentomeechai, T. et al. A pipeline for studying and engineering singlesubunit oligosaccharyltransferases. Methods Enzymol. 597, 55-81 (2017).

67. Jewett, M. C. \& Swartz, J. R. Mimicking the Escherichia coli cytoplasmic environment activates long-lived and efficient cell-free protein synthesis. Biotechnol. Bioeng. 86, 19-26 (2004).

68. Pettersen, E. F. et al. UCSF Chimera-a visualization system for exploratory research and analysis. J. Comput. Chem. 25, 1605-1612 (2004).

\section{Acknowledgements}

We thank Judith Merritt (Glycobia, Inc.) for providing plasmid pMW07-pgl $\Delta \mathrm{B}, \mathrm{Bil}$ Clemons (California Institute of Technology) for plasmids encoding various PglB homologs, and Markus Aebi for providing plasmid pACYCpgl2 and hR6 serum used in this work. We thank Mr. Robert Sherwood from the Cornell Proteomics and Mass Spectrometry Facility for his technical assistance acquiring the LC-MS/MS raw data files. We thank Weston Kightlinger and James Kath for providing plasmid pJL1-hEPO that was used to generate the EPO variants used in this study. Finally, we thank Jasmine Hershewe for critical discussions and sharing of reagents and ideas. This work was supported by the Defense Threat Reduction Agency (GRANT11631647 to M.P.D., M.C. J., and M.M.), National Science Foundation (Grants \# CBET 1159581 and CBET 1264701 both to M.P.D. and MCB 1413563 to M.P.D. and M.C.J.), the David and Lucile Packard Foundation, and the Dreyfus Teacher-Scholar program. T.J. was supported by a Royal Thai Government Fellowship. J.C.S. and C.J.G. were each supported by a National Science Foundation Graduate Research Fellowship.

\section{Author contributions}

T.J. and J.C.S. designed research, performed all research, analyzed all data, and wrote the paper. A.N., C.G., L.E.Y., and K.J.H. performed research. M.M. aided in data interpretation. M.C.J. and M.P.D. directed research, analyzed data, and wrote the paper.

\section{Additional information}

Supplementary Information accompanies this paper at https://doi.org/10.1038/s41467 018-05110-x.

Competing interests: M.P.D. has a financial interest in Glycobia, Inc. and Versatope, Inc. M.P.D.'s interests are reviewed and managed by Cornell University in accordance with their conflict of interest policies. The remaining authors declare no competing interests.

Reprints and permission information is available online at http://npg.nature.com/ reprintsandpermissions/

Publisher's note: Springer Nature remains neutral with regard to jurisdictional claims in published maps and institutional affiliations.

\footnotetext{
Open Access This article is licensed under a Creative Commons Attribution 4.0 International License, which permits use, sharing, adaptation, distribution and reproduction in any medium or format, as long as you give appropriate credit to the original author(s) and the source, provide a link to the Creative Commons license, and indicate if changes were made. The images or other third party material in this article are included in the article's Creative Commons license, unles indicated otherwise in a credit line to the material. If material is not included in the article's Creative Commons license and your intended use is not permitted by statutory regulation or exceeds the permitted use, you will need to obtain permission directly from the copyright holder. To view a copy of this license, visit http://creativecommons.org/ licenses/by/4.0/.
}

(C) The Author(s) 2018 